\title{
White adipose tissue inflammation is not attenuated by short-term calorie restriction in obese humans
}

1 Julia Sbierski-Kind ${ }^{1,2,3,4^{*}}$, Knut Mai, ${ }^{1,2,6}$, Jonas Kath ${ }^{1,3}$, Anke Jurisch,4, , Mathias Streitz ${ }^{3,4}$, 2 Leon Kuchenbecker ${ }^{3,4}$, Karsten Jürchott ${ }^{3,4}$, Leonard Spranger, ${ }^{1,6}$, Reiner Jumpertz von 3 Schwartzenberg ${ }^{1,2,6,7}$, Anne-Marie Decker ${ }^{1,2}$, Ulrike Krüger ${ }^{3,4}$, Hans-Dieter Volk ${ }^{3,4,5}$, Joachim Spranger ${ }^{1,2,6,7 \dagger}$

${ }^{1}$ Charité - Universitätsmedizin Berlin, Corporate Member of Freie Universität Berlin, Humboldt-

7 Universität zu Berlin, and Berlin Institute of Health, Department of Endocrinology \& Metabolism,

8 Berlin, Germany.

$9 \quad{ }^{2}$ Berlin Institute of Health (BIH), Berlin, Germany.

$10{ }^{3}$ Berlin Institute of Health Center for Regenerative Therapies (BCRT), Charite University Medicine 11 Berlin, Berlin, Germany.

$12{ }^{4}$ Institute for Medical Immunology, Charité University Medicine Berlin, Berlin, Germany.

$13{ }^{5}$ Berlin Center for Advanced Therapies, Charité University Medicine Berlin, Berlin, Germany.

$14{ }^{6}$ Charité-Center for Cardiovascular Research (CCR), Berlin, Germany.

$15{ }^{7}$ German Center for Cardiovascular Research (DZHK), partner site Berlin.

$17 \dagger$ Both authors contributed equally to this work as senior authors.

\section{* Correspondence:} Julia Sbierski-Kind, Charité - Universitätsmedizin Berlin, Medizinische Klinik für Endokrinologie und Stoffwechselmedizin, Charitéplatz 1, 10117 Berlin, Germany; Email: julia.sbierski-

22 kind@charite.de 


\section{Abstract}

Obesity is a growing global health problem due to its association with chronic low-grade inflammation contributing to metabolic complications. Multiple studies indicate that white adipose tissue (WAT) inflammation can promote type 2 diabetes. However, the function and regulation of both innate and adaptive immune cells in human WAT under conditions of obesity and calorie restriction (CR) is not fully understood yet. Using a randomized interventional design, we investigated postmenopausal obese women who either underwent $\mathrm{CR}$ for three months followed by a 4 weeks phase of weight maintenance or had to maintain a stable weight over the whole study period. A comprehensive immune phenotyping protocol was conducted using validated multiparameter flow cytometry analysis in blood and subcutaneous WAT (SAT) $(n=21)$. The T cell receptor repertoire was analyzed by next generation sequencing $(n=20)$ and cytokine levels were determined in SAT $(\mathrm{n}=22)$. Metabolic parameters were determined by hyperinsulinemic-euglycemic clamp and then correlated to immune cell subsets. We found that insulin resistance (IR) correlates significantly with a shift towards the memory $\mathrm{T}$ cell compartment in SAT. Among various $\mathrm{T}$ cell subsets, predominantly $\mathrm{CD}^{+}$effector memory $\mathrm{T}$ cells were associated with obesity-related IR. Interestingly, $\mathrm{T}$ cell receptor analysis revealed a diverse repertoire in SAT arguing against an antigen-driven intraSAT expansion of effector memory $\mathrm{T}$ cells. Surprisingly, neither inflammatory cytokine levels nor leucocyte subpopulations were significantly altered upon CR. Our findings demonstrate the accumulation of effector memory T cells in obese SAT contributing to chronic inflammation. The long-standing effect of obesity-induced changes in SAT was demonstrated by preserved immune cell composition after short-term CR induced weight loss. 


\section{Introduction}

Obesity is a complex disorder involving an excessive amount of body fat. It is associated with reduced quality of life and with the leading causes of death worldwide, including cardiovascular diseases, stroke, diabetes and some types of cancer (1-4). The prevalence of obesity has risen dramatically over the past decades. Today, 2.1 billion people - nearly $30 \%$ of the world's population - are either obese or overweight (5). Obesity-associated IR promotes type 2 diabetes (T2D), when exhausted islet $\beta$ cells fail to compensate for the increased need for insulin to maintain glucose homeostasis (6). Low-grade inflammation of hypertrophic WAT plays an etiologic role in the development of IR (7-9). Specifically, it has been found that excessive energy intake, accompanied by chronically elevated levels of blood glucose, triglycerides and free fatty acids, seems to alter components of the immune system $(10,11)$. These immunological changes include altered levels of cells of the innate immune system, particularly macrophages $(12,13)$. It has been established that the polarization into pro-inflammatory "M1" or alternatively activated "M2" macrophages influences adipose tissue homeostasis with M1 macrophages promoting inflammation while M2 macrophages help to maintain adipose tissue homeostasis, including insulin sensitivity in lean adipose tissue (14). Mast cells, neutrophils and dendritic cells are shown to exacerbate IR (15-17), whereas eosinophils and innate lymphoid cells seem to be protective (16). Whereas previous research mainly focused on innate immunity, adaptive immune cells ( $\mathrm{T}$ - and $\mathrm{B}$ cells) have emerged as important regulators of glucose homeostasis. They exert inflammatory (including CD8 ${ }^{+} \mathrm{T}$ cells, Th1, Th17, and B cells) or regulatory influences (including regulatory $\mathrm{T}$ (Treg) cells, Th2 cells) and can both exacerbate or protect against IR (18-20). In particular, it has been found that the helper $\mathrm{T}$ cell composition in peripheral blood correlates significantly with the homeostasis model of assessment for insulin resistance index (HOMA-IR) (21) and other measures of adiposity, inflammation and glucose intolerance $(22,23)$. T cells have also been identified in human WAT (24-27), but studies elucidating their relationship to local and systemic inflammation and IR and the impact of CR on them are limited. Whereas obesity has been clearly linked to IR and T2D, CR is known to reduce the incidence of heart and kidney disease, hypertension and neurological disorders, to increase sensitivity to insulin, and to be associated with increased longevity $(28,29)$. It is unclear if obesity-related immune cell alterations could be reversed by CR. Studies in the murine spleen, lung, liver and lymph nodes recently found that long-term $\mathrm{CR}$ preserves a naïve T-cell phenotype and an immature NK cell phenotype as mice age (30). Moreover, is has been reported that both exercise and CR modulate innate and adaptive immunity as well as cytokine levels in inguinal adipose tissue and the spleen in mice $(31,32)$. On the other side, long-term CR is thought to decrease the production of peripheral B lymphocytes and to impair immune function (33). Conversely, observations in human studies supported the notion that 6-month CR enhances T-cell-mediated immune response in peripheral blood (34). In another multi-center, randomized clinical trial it has been reported that long-term moderate CR reduced circulating inflammatory markers (35). Contrastingly, previous work has provided evidence that long-term CR is not associated with T cell immunosenescent markers (36). Altogether, there is limited and partially controversial information on the effect of CR on the adaptive immune system in human adipose tissues. To better characterize leucocytes, including $\mathrm{T}$ cells, that accumulate in SAT with obesity, to investigate the impact of CR and to further assess potential mechanisms of weight regain after CR, we conducted a sub-study in 21 participants of a randomized controlled clinical trial with obese participants. Here, we compared leucocyte subsets in peripheral blood and SAT, as well as insulin and glucose metabolism and determined the levels of cytokine secretion in SAT directly after the CR induced weight loss and after a period of maintaining the reduced weight. In addition, the TCR-repertoire of intra-SAT T cells was analyzed by next 112 generation sequencing. On the basis of previous animal experiments $(18,19)$, we hypothesized that
113 cytokine levels as well as inflammatory leucocyte cell numbers would correlate with metabolic 
114 measures. Moreover, we expected that CR would impact inflammation in obese probands directly

115 after weight loss, demonstrated by altered numbers of leucocytes and inflammatory cytokines.

\section{Materials and Methods}

\section{Study Design and Adipose Tissue Sampling}

119 In overweight or obese (body mass index (BMI) $>27 \mathrm{~kg} / \mathrm{m}^{2}$ ) probands, whole blood and SAT 120 biopsies were sampled before (M0), after weight loss induced by a 12-week low-calorie diet (M3) and after having maintained weight stable over a 4 week period following an isocaloric diet (M4). SAT biopsies were collected by percutaneous needle biopsy of periumbilical fat depots using a 15gauge needle through skin and anesthetized with $1 \%$ lidocaine, as described before (37). Blood was obtained at approx. 8 a.m. at time points 0,3 and 4 months, collected into vacutainers (Thermo Fisher Scientific) containing EDTA (Sigma-Aldrich) for anticoagulation and stored at $4^{\circ} \mathrm{C}$ for maximum 4 hours. Anthropometry was performed by trained staff under standardized conditions. Results were compared to an obese control group instructed to maintain their weight during the course of the study. Furthermore, blood test results at baseline were compared to a lean control group. Fig. 1A illustrates an overview of the study.

\section{Participants}

132 The study was performed as a sub-study of a larger study focusing on muscle mass regulation 133 "Effects of negative energy balance on muscle mass regulation" (registered at 134 https://clinicaltrials.gov, NCT01105143) at the Department of Endocrinology of the Charite University Medicine Berlin, Germany. The study was conducted in compliance with the International Conference on Harmonization Guidelines for Good Clinical Practice and the Declaration of Helsinki. All subjects provided written informed consent before participating in this study. The add-on protocol of the study was approved by the local Ethics Committee of the Charité Universitätsmedizin Berlin (EA2/050/10). Inclusion criteria comprised a BMI > $27 \mathrm{~kg} / \mathrm{m}^{2}$ and postmenopausal status. The presence of concomitant immunological illness, history of severe untreated medical, neurological, and psychiatric diseases which may interfere with the planned interventions, such as instable coronary heart disease, kidney and liver disease, systemic infections, endocrinological disorders, and hypertension (systolic blood pressure $>180 \mathrm{~mm} \mathrm{Hg}$, diastolic blood pressure $>110 \mathrm{~mm} \mathrm{Hg}$ ) were excluded by medical history assessment in obese and lean subjects. Exclusion criteria were also changing dieting or smoking habits significantly in the last two months including a weight loss of $5 \mathrm{~kg}$ or more. Cytokine levels of SAT lysates were analyzed in a subgroup of 22 probands before (M0), directly after the calorie restriction period (M3) and after the weight maintenance period (M4) (sub-study A). Blood and SAT T cell receptor sequencing was performed in a subgroup of 20 probands before the CR period (M0) (sub-Study B). Immune cell composition in blood and SAT tissue before and after weight loss was studied in a total of 21 overweight and obese women via flow cytometry (sub-Study C). The 21 women were sequentially included into this substudy, providing additional study consent. Subjects were randomly assigned to the CR group and control group. 8 subjects were not available for all follow-up testing sessions due to personal reasons (half of them were assigned to the CR group). Finally, 11 subjects were available for the per-protocol analysis of sub-Study C (CR group: $\mathrm{n}=5$, control group: $\mathrm{n}=6$ ). Healthy and lean (BMI $<25 \mathrm{~kg} / \mathrm{m}^{2}$ ) age-matched female individuals $(\mathrm{n}=16)$ were recruited from staff of Charité - Universitätsmedizin Berlin, Berlin, Germany. The participants gave their written and informed consent prior to participating in the study. The study was approved by the institutional review board (IRB: 
Ethikkommision der Charité). Characteristics of the subjects analyzed for immune cell composition tested via flow cytometry before and after weight loss are shown in Table 1. Subjects from both CR group and control group were comparable with regard to age, BMI, waist circumference and leucocyte numbers (all $P>0.05$ ). Characteristics of subjects analyzed for SAT cytokine secretion are shown in Table 1. Characteristics analyzed for T cell receptor sequencing are also shown in Table 1. Subjects from all groups were comparable with regard to age.

\section{Calorie Restriction Intervention}

In the intervention group, weight loss was induced by low calorie diets. Furthermore, life-style changes were implemented via weekly counseling sessions by clinical dieticians. In the first eight weeks of the 12-week weight loss phase, weight loss was assisted by a low-calorie formula diet (800 $\mathrm{kcal} / \mathrm{d}$ ) replacing all meals with a formula diet (Optifast 2®, Nestlé HealthCare Nutrition GmbH, Frankfurt/Main, Germany). Participants were advised to consume the formula diet exclusively (daily consumption of five packets with $160 \mathrm{kcal}$ each: $20 \mathrm{~g}$ carbohydrates, $14 \mathrm{~g}$ proteins, and $3 \mathrm{~g}$ fat dissolved in $300 \mathrm{ml}$ water) without consuming any additional food. The eight weeks of formula diet were followed by four weeks in which the formula diet was substituted by a calorie reduced healthy diet to facilitate further weight loss $(\sim 1300 \mathrm{kcal} / \mathrm{day})$. Meals in this diet consisted of a balanced mix of macronutrients in accordance to the guidelines of the German Society for Nutrition (50-55\% carbohydrates, $15-20 \%$ proteins, and $30 \%$ fat). The recommended daily calorie intake during these four weeks was based on the measured resting energy expenditure and adapted with regard to subsequent weight changes. Additionally, participants were encouraged to increase physical activity to 150 min of activity per week at least and step counting devices were handed out to monitor and motivate for physical activity. However, no intervention regarding physical exercise was performed. After the 12-weeks weight loss phase, subjects were advised to maintain reduced weight over additional four weeks (until M4). In this weight maintenance phase, subjects were instructed to follow an isocaloric diet. The isocaloric diet was specified individually and subjects were advised to consume a balanced mix of foods with the following distribution: 50-55 \% carbohydrates, $30 \%$ fat, $15-20 \%$ proteins. Figure 1B shows that subjects of the intervention group were able to reduce BMI significantly and to maintain weight thereafter. Subjects in the control group were advised to live a healthy lifestyle but maintain weight during the course of the study.

\section{Hyperinsulinemic-Euglycemic Clamp Procedure}

The hyperinsulinemic-euglycemic clamp was performed as described previously $(38,39)$. Briefly, 40 $\mathrm{mIU} \cdot \mathrm{m}^{-2} \cdot \mathrm{min}^{-1}$ human insulin (Actrapid, Novo Nordisk) and a variable infusion of $10 \%$ glucose (Serag Wiessner) were used. Capillary glucose concentration was then monitored every five minutes and was maintained between 4.0 and $4.9 \mathrm{mmol} / \mathrm{L}$ by varying the glucose infusion rate. Insulin sensitivity was assessed as $M$-value and was calculated by dividing the average glucose infusion rate (milligrams glucose per minute) during the steady state of the clamp by the body weight. The insulin

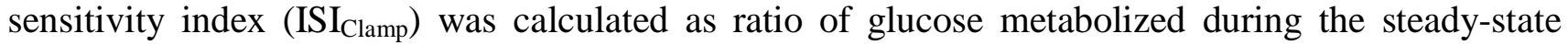
period ( $M$-value) to a mean serum insulin concentration (milliunits per liter) in this period during the euglycemic clamp. Blood samples were collected before the clamp and at least two hours after starting the clamp during steady-state conditions. Blood samples were centrifuged, and serum and plasma samples were frozen immediately at $-80^{\circ} \mathrm{C}$. 


\section{Adipose Tissue Cell Isolation}

205

206

207

208

209

210

211

212

213

214

215

216

217

218

219

220

221

222

223

224

225

226

227

228

229

230

231

232

233

234

235

236

237

238

239

240

241

242

243

244

Cells of the stroma vascular fraction were obtained by collagenase digestion of SAT for 90 minutes at $37^{\circ} \mathrm{C}$ on a rotation shaker $(200 \mathrm{rpm})$. The homogenate was then filtered and centrifuged twice at $500 \mathrm{~g}$ for 10 minutes at $4^{\circ} \mathrm{C}$. Stroma vascular fraction cells were resuspended in endotoxin-free PBS (Sigma-Aldrich) supplemented with $2 \%$ fetal calf serum (FCS, PAA) and $0.1 \%$ sodium azide (Sigma-Aldrich) and stored at $4^{\circ} \mathrm{C}$ until the staining was proceeded.

\section{Antibody Panel}

Fluorochrome-conjugated (FITC, PE, ECD, PC7, APC, APC-A700, APC-A750, PacBlue and KrOrange) anti-human monoclonal antibodies were used to stain 30 different epitopes. All antibodies were obtained from Beckman Coulter, except anti-BDCA-2 and anti-BDCA-3, which were obtained from Miltenyi Biotec, and anti-CCR7, which was obtained from R\&D Systems. Six panel matrices for 7- to 9-fluorochrome channels defined and validated by the ONE Study consortium as well as gating strategies were used based on published results (40).

\section{Leukocyte Staining}

For staining $100 \mu \mathrm{L}$ of anticoagulated peripheral blood or $100 \mu \mathrm{l}$ of SAT stroma vascular fraction cells were stained with surface antibodies for 15 minutes at room temperature in the dark prior to lysis and fixation with VersaLyse $+2.5 \%$ IOTest fixative solution (Beckman Coulter) for 15 minutes in the dark. Intracellular staining was performed with the PerFix-nc Kit (Beckman Coulter) and cells were stained with intracellular antibodies for 1 hour. Lysed cells were washed twice (PBS, and PBS containing $2 \% \mathrm{FCS}$ and $0.1 \%$ sodium azide) prior to acquisition. Cell staining was performed within 4 hours after blood collection as recommended in published results to reduce variability. All samples were measured on 10 color, 3 laser Navios flow cytometers (Beckman Coulter) and acquired data files were analyzed using the Kaluza software, version 1.2 (Beckman Coulter). Cell doublets were excluded using forward scatter time of flight (wide) versus forward scatter integral (area). Leukocytes were defined gating CD45 expression versus side scatter. Absolute counts of the subpopulations were calculated in all panels by use of the $\mathrm{CD}^{+} 5^{+}$leukocyte 'backbone' in combination with the cell count obtained from all samples. Cells were plotted using color density biexponential displays to ensure correct identification of negative and positive cell populations.

\section{PBMC Isolation and Cryopreservation}

All steps of peripheral blood mononuclear cells (PBMC) preparation were carried out at room temperature. The content of the blood collecting tubes from the same probands were pooled and mixed 1:1 with pre-warmed 1×PBS. The blood:PBS mixture was carefully layered onto Biocoll (Biochrom) and subsequently centrifuged for density gradient at $1000 \mathrm{~g}$ for $20 \mathrm{~min}$, at room temperature (slow acceleration, no brake). The ring-shape interphase (containing PBMCs) was collected with a Pasteur pipette into a new $50 \mathrm{ml}$ tube and diluted up to $50 \mathrm{ml}$ with pre-warmed $1 \times \mathrm{PBS}$ and centrifuged with $300 \mathrm{~g}$ for $10 \mathrm{~min}$, at room temperature, with fast acceleration and with brake. The number of living cells was determined with Trypan blue exclusion as number of living cells $/ \mathrm{ml}$ of blood. Following a further washing step in $1 \times \mathrm{PBS}$ (300 g, $10 \mathrm{~min}$, room temperature), 
cells were resuspended in freezing media containing fetal calf serum (FCS, PAA) with $10 \%$ dimethyl-sulfoxide (DMSO, Sigma-Aldrich) $1 \mathrm{ml}$ aliquots with $5 \times 10^{6}$ cells $/ \mathrm{ml}$ were gradually frozen in a freezing container at $-80^{\circ} \mathrm{C}$ for at least 48 hours and transferred into a cryo tank (liquid nitrogen vapor phase).

\section{T Cell Receptor Sequencing}

Genomic DNA was isolated using the QIAamp DNA Mini Kit (Qiagen) according to manufacturer's instructions for sequencing of T-cell receptors (TCRs). Libraries for TCR- $\beta$ subunit profiling were prepared utilizing the hsTCRb Kit (Adaptive Biotechnologies) following the manufacturer's instructions and sequencing was performed on Illumina. Thereafter, ImmunoSEQ-Analyzer 3.0 software was used for sequencing data analysis. Briefly, the most variable complementarydetermining region 3 (CDR3), spanning the recombination site of V-D-J recombinations of TCR- $\beta$ chains was sequenced, as previously described (41). Reads with an average quality score below 20 were removed from the analysis. The remaining reads were processed and further analyzed using IMSEQ as previously performed by Kuchenbecker et al. (42). For estimating the diversity of the TCR repertoire, the Shannon Entropy option was used (ShannonWienerIndex_mean value/100).

\section{Cytokine Assay}

The protein levels of IL-6, IL-13, IL-7, IL-8, MIP-1a, MIP-1b, MIP-3a, ITAC and Fractalkine in Cytokine Magnetic Bead Panel (Millipore Sigma).

\section{Statistical Analysis}

The results are shown as the mean \pm SEM. All statistical analysis was performed using GraphPad Prism version 8 (GraphPad Software, San Diego, CA) and R version 3.2.1, available free online at https://www.r-project.org. Unless otherwise notified, no mathematical correction was made for

271

272 multiple comparisons in order to reduce the error of the second kind. Depending on the distribution of data, Pearson simple coefficient or Spearman rank correlation coefficient were used for correlation analysis. Mann-Whitney $U$ test or Student $t$ test were applied to estimate differences between groups. Repeated-measures two-way ANOVA, multiple testing with Bonferroni correction and a linear mixed effector model with False discovery rate (FDR) and Bonferroni correction were used to analyze time courses. Significant differences were assumed for $\mathrm{P}<0.05$ (two-tailed). 


\section{Results}

285

286

287

288

289

290

291

292

293

294

295

296

297

298

299

300

301

302

303

304

305

306

307

308

309

310

311

312

313

314

315

316

317

318

319

320

321

322

323

324

325

326

327

\section{Obese Probands Have a Decreased Proportion of Effector Memory $\mathrm{CD8}^{+} \mathrm{T}^{\mathrm{Cells}}$ Associated with an Enhanced CD4/8 T Cell Ratio in Peripheral Blood}

First, we performed multiparameter flow cytometric analyses to determine whether the composition of leucocyte cell subpopulations is affected in the peripheral blood of obese probands at the starting time point of the study (M0) compared to age and sex-matched healthy lean probands ( $\mathrm{n}=21 \mathrm{vs}$. 16). For this purpose we employed the so-called "ONE study" flow cytometry panels consisting of six leucocyte profiling 10-color panels, which has been designed and extensively validated in multicenter trials in our lab (40). We did not reveal significant differences in the numbers of total leucocytes or major leucocyte subpopulations (Figure 2A). Subset analyses, however, showed an increased percentage of activated monocytes $\left(\mathrm{CD} 14^{+} \mathrm{CD} 16^{\text {high }}\right)$ in obese subjects $(P=0.020$, data not shown), suggesting a proinflammatory state, which is consistent with previous literature (7-9). However, we observed an increase of the naïve compartment of $\mathrm{CD}^{+}$and $\mathrm{CD} 8^{+} \mathrm{T}$ cells within the circulating $\mathrm{T}$ cells in the obese cohort whereas percentages of central memory, effector memory and terminally differentiated $\mathrm{T}$ cells were not significantly different between lean and obese probands (Figure 2B). Also, absolute counts of naïve $\mathrm{CD}^{+} \mathrm{T}$ cells were increased (Figure 2C) whereas effector memory $\mathrm{CD}^{+} \mathrm{T}$ cells (Figure 2C) were reduced in obese probands. The analysis of B cell subtypes showed that obese subjects have higher numbers of naïve B cells (Figure 2D). These results are partly in line with recently published observations (43) demonstrating a selective increase of peripheral blood $\mathrm{CD}^{+} \mathrm{T}$ cells skewed toward an anti-inflammatory phenotype $\left(\mathrm{CD} 4^{+}\right.$naïve, natural $\mathrm{CD} 4^{+} \mathrm{CD} 25^{+} \mathrm{FoxP} 3^{+}$Treg, and Th2 $\mathrm{T}$ cells) in morbidly obese human subjects. Taken together, our data demonstrate that obesity is associated with a shift toward naïve T cells in both $\mathrm{CD} 4^{+}$and $\mathrm{CD} 8^{+}$ compartments in peripheral blood.

\section{Alterations of Systemic Leucocyte Subpopulations Correlate with Metabolic Measures in Obesity}

To further assess the association of metabolic parameters with the altered systemic immune cell composition in obesity, we examined the correlations between BMI, insulin sensitivity index

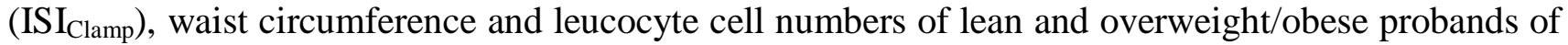
the sub-study C. A significant correlation was found between the BMI and total leucocyte numbers $(r$ $=0.367, P=0.035$, Figure 3A). Moreover, BMI correlated positively with the number of activated $\mathrm{CD} 14^{+} \mathrm{CD} 16^{\text {high }}$ monocytes $(r=0.459, P=0.007$, Figure $3 \mathrm{~B})$. Additionally, we found positive correlations for BMI with naïve and central memory CD4 ${ }^{+}$T-cell numbers $(r=0.401, P=0.046 ; r=$ $0.682, P<0.001$, Figures $3 \mathrm{C}, \mathrm{D})$ but not with effector memory or terminally differentiated effector memory $\mathrm{CD}^{+} \mathrm{T}$ cell numbers (Supplementary Table 1). Similarly, a significant correlation between BMI and naïve $\mathrm{CD}^{+}$T-cell numbers $(r=0.483, P=0.014$, Figure $3 \mathrm{E})$ but not with other $\mathrm{CD}^{+} \mathrm{T}^{-}$ cell subsets (Figure 3F, Supplementary Table 1) was found. Additionally, absolute numbers of lymphocytes $(r=0.494, P=0.027)$, T cells $(r=0.545, P=0.013), \mathrm{CD}^{+}(r=0.475, P=0.034)$ and $\mathrm{CD}^{+} \mathrm{T}$ cells $(r=0.452, P=0.045)$, and TCR $\alpha \beta$ cells $(r=0.564, P=0.009)$ correlated positively with waist circumference (Supplementary Table 1). Insulin and glucose levels were determined in the

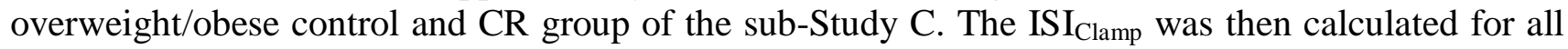
obese probands as a measure of insulin-mediated glucose uptake. Only total leucocyte $(r=-0.482, P$ $=0.031)$ and monocyte $(r=-0.519, P=0.019)$ cell counts correlated negatively (and thus reciprocally with $\mathrm{BMI}$ ) with $\mathrm{ISI}_{\text {Clamp }}$ (Figure $3 \mathrm{G}, \mathrm{H}$ ). While, the percentage of $\mathrm{B}$ cells correlated 
positively with $\operatorname{ISI}_{\text {Clamp }}(r=0.498, P=0.022$, Figure $3 \mathrm{I})$, in the $\mathrm{T}$ cell compartment, a significant correlation could only be found for the percentage of naïve $\mathrm{CD}^{+} \mathrm{T}$ cells $(r=0.561, P=0.008$, Figure 3J, Supplementary Table 2). Using chemokine receptor panels, we further analyzed the distribution of functional T cell subsets. Recently, a role of Th17 and Th22 cells in obesity-mediated IR has been described (21). Th17-derived Th1 cells have been termed non-classic Th1 cells and can be identified based on their constant CCR6 expression. Here, we found a significant correlation of non-classic Th1 cells with ISI $_{\text {Clamp }}(r=0.662, P=0.002$, Figure $3 \mathrm{~K})$. These results are not consistent with published reports showing that adipose-associated Th1 cells promote obesity-associated inflammation $(44,45)$. To determine whether the shift to a more naïve T-cell composition in peripheral blood of obese probands is due to migration of the effector memory $\mathrm{T}$ cells to the adipose tissues, we next studied intra-SAT cell composition.

\section{Intra-SAT Accumulation of Effector Memory T Cells Correlates with ISI in Obesity}

To ascertain the relationship between $\mathrm{T}$ cell profiles and metabolic measures during obesity, we investigated the correlations between BMI, waist circumference and systemic IR and leucocyte cell numbers in SAT of overweight/obese probands of the sub-study C. To our knowledge, this is the first reported broad characterization of immune cell subsets in human SAT using a highly standardized assay. We observed an increased percentage of granulocytes in SAT compared to paired blood samples, but decreased lymphocyte counts (Figure 4A). Interestingly, within both the CD4 ${ }^{+}$and the $\mathrm{CD}^{+} \mathrm{T}$-cell compartment, increased percentages of effector memory $\mathrm{T}$ cells were found in SAT, whereas naïve and central memory $\mathrm{T}$-cell percentages were decreased and no differences were found in terminally differentiated effector memory T cells (TEMRAs) (Figures 4B-D). Interestingly, naïve and effector memory $\mathrm{CD}^{+} \mathrm{T}$ cells, but no other memory and effector T-cell subsets correlated with the $\mathrm{ISI}_{\text {Clamp }}(r=0.485, P=0.026 ; r=-0.738, P<0.001$, Figures 4E-F). Although the frequency of central memory $\mathrm{CD}^{+}$and $\mathrm{CD} 8^{+} \mathrm{T}$ cells was lower in SAT compared to paired blood samples, they correlated positively with the BMI ( $r=0.548, P=0.010 ; r=0.482, P=0.027$, respectively) whereas TEMRA cell number was inversely correlated with BMI $(r=-0.566, P=0.008$, Supplementary Table 3 , respectively). No significant correlations with metabolic measures (BMI, waist circumference,

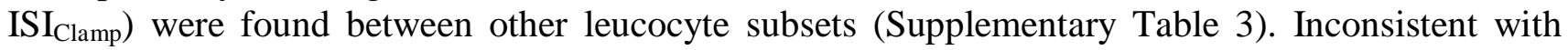
previous results $(24,46)$, we could hardly detect any Th22-like or Th17-like cells, although they were detectable in peripheral blood (data not shown). However, all other immune cell subsets were consistently detectable. Overall, these results suggest that the accumulation of effector memory $\mathrm{T}$ cells in human SAT is associated with IR. The drop in effector memory T cell counts in the blood of the obese probands might result from migration into the inflamed SAT.

\section{Characterization of the SAT TCR-B Repertoires of Obese Probands Revealed Preserved TCR Diversity}

T cells can be identified via their unique TCR sequence. Given the involvement of the adaptive immune system and strong correlations of effector memory T cell subsets with metabolic parameters, we analyzed the TCR repertoire of SAT and blood derived T cells to address the question whether unspecific bystander expansion or an (auto)-antigen-driven process is the main driver of effector memory $\mathrm{T}$ cell accumulation in obese SAT. We compared clonal relations between SAT and blood derived $T$ cells of 20 obese probands (sub-study B) at M0. TCR- $\beta$ chain repertoire analysis of adipose $\mathrm{T}$ cells by next generation sequencing revealed a polyclonal repertoire with overlapping TCRs with peripheral blood $\mathrm{T}$ cells, suggesting that there was no strong skewing towards particular T cell clones or a unique SAT repertoire. Applying the Shannon Entropy algorithm (47) and 
374

375

376

377

378

379

380

381

382

383

384

385

386

387

388

389

390

391

392

393

394

395

396

397

398

399

400

401

402

403

404

405

406

407

408

409

410

411

412

413

414

415

416

417

418

normalizing the number of unique $\mathrm{T}$ cell clonotypes by the total number of sequences per sample, the diversity of the TCR repertoire was assessed using the total number of unique TCR- $\beta$ clonotypes in blood and SAT samples and revealed a very similar degree of diversity with values close to 1 , as shown in Figure 5A. The frequencies of the top 100 clones in SAT and blood are shown in Figure 5B.

\section{Short-Term CR Does Not Reverse the Shift of Effector Memory T Cells from Blood to SAT and the Local Release of Inflammatory Cytokines Despite Positive Metabolic Effects}

To assess the effects of CR on immunological alterations, we investigated the kinetics of leucocyte subsets in blood and SAT of obese probands prior to weight loss and then 3 and 4 months after compared to a control group that maintained a stable weight (sub-study C). Interestingly, we did not find any significant decrease in the total number of leucocytes after correction for multiple testing with Bonferroni or FDR although they were highly correlated with BMI (Figure 6A). The linear mixed model testing for group $\mathrm{x}$ time interactions for total numbers and percentages of leucocyte subsets revealed no significant group $\mathrm{x}$ time interactions at time points M3 and M4 in SAT or peripheral blood indicating no significant difference in leucocyte subset composition between the groups after the weight reduction and weight maintenance phase in the intervention group in comparison with the control group. Most notably, the percentage of all $\mathrm{T}$ cell subsets, including naïve, central memory, effector memory and terminally differentiated effector memory $\mathrm{T}$ cells, remained completely unaffected (Supplementary Table 4). We next studied the impact of CR on intra-SAT cytokine levels with a multiplex assay in 22 obese probands (sub-study A), as the association between obesity and increased release of pro-inflammatory cytokines is well known. MIP-1a correlated positively with the BMI $(r=0.588, P=0.018$, Figure $6 \mathrm{~K})$, while MIP-3a correlated negatively with $\operatorname{ISI}_{\text {Clamp }}(\mathrm{r}=-0.433, P=0.044)$. Both cytokines are inducible $\mathrm{C}-\mathrm{C}$ family chemokines that play a pivotal role in the recruitment of monocytes, macrophages (MIP-1a) and lymphocytes (MIP-3a) (48, 49) (Figure 6L and Supplementary Table 5). Additionally, HOMA correlated positively with MIP-1a $(\mathrm{r}=0.584, P=0.009)$, MIP- $1 \mathrm{~b}(\mathrm{r}=0.555, P=0.011)$ and MIP-3a ( $\mathrm{r}=0.524, P=0.018$ ) (data not shown). To our surprise, intra-SAT levels of IL-6, IL-13, IL-7, IL-8, MIP-1a, MIP-1b, MIP-3a, ITAC and Fractalkine were not significantly influenced by CR-induced weight loss, as shown in Figure 6B-J. Taken together, our data show that the immune cell phenotype in blood and SAT is not substantially altered after CR despite metabolic improvements.

\section{Discussion}

This study performs, for the first time, a comprehensive immune monitoring of human blood and SAT tissue using flow cytometry in a standardized assay, which includes six leucocyte profiling panels and which yields acceptable variability tested at multiple international sites (40), allowing unmanipulated analysis of changes in absolute cell numbers of leukocyte subsets in SAT of obese individuals. Although impressive findings have been demonstrated in rodent studies, the immune cell composition in human WAT is unclear and there are no studies providing standardized immune monitoring of leucocyte subsets in human WAT before and after weight loss induced by CR. To our knowledge, there are only few studies investigating various $\mathrm{T}$ cell subsets in human WAT using flow cytometry. First, increased prevalence of Th17 and Th22 cells has been shown in SAT of metabolically abnormal versus metabolically healthy obese subjects (24). Second, a specific accumulation of IL-22 and IL-17 producing $\mathrm{CD}^{+}$T cells was found in SAT of type 2 diabetic obese patients (46). Furthermore, an increased frequency of Th17 cells was demonstrated in SAT of overweight versus lean women (50). Flow cytometry revealed significant correlations between waist circumference and levels of activation marker expression on $\mathrm{CD}^{+}$and $\mathrm{CD} 8^{+} \mathrm{T}$ cells in SAT (51). 
Only recently, the association of $\mathrm{CD}^{+} \mathrm{T}$ cells in visceral WAT with their counterparts in SAT was investigated in lean and obese men (52).

We confirm prior studies demonstrating various $\mathrm{T}$ cells are present in human adipose tissues. Importantly, our results demonstrate that subpopulations of $\mathrm{T}$ cells are associated with both body weight and systemic IR. In obese women, pro-inflammatory effector memory $\mathrm{CD}^{+} \mathrm{T}$ cells were markedly increased in SAT relative to peripheral blood, which was associated with a shift to enhanced levels of naïve $T$ cells in the circulation. Numbers of both naïve and effector memory $T$ cells showed robust bidirectional relationships to BMI. Importantly, IR correlates positively with effector memory $\mathrm{CD}^{+} \mathrm{T}$-cell counts and negatively with naïve $\mathrm{CD} 8^{+} \mathrm{T}$ cells counts in SAT. Due to their specific chemokine, adhesion, and homing receptor profile, effector memory $\mathrm{T}$ cells can enter any given inflamed site, while naïve and central memory $\mathrm{T}$ cells circulate in the blood and the lymphatic system. Moreover, effector memory $\mathrm{T}$ cells can be activated easier by bystander activation and do not depend on TCR signals. The release of proinflammatory cytokines, such as TNF $\alpha$ and IFN $\gamma$ can trigger inflammation with accumulation and activation of other leucocyte subsets, such as myeloid cells further amplifying inflammation in adipose tissues. In fact, SAT expression of MIP-1a (as well as MIP-3b and MIP-3a), a chemokine recruiting monocytes and macrophages to peripheral tissues, was highly associated with BMI. Altogether, the relative dominance of antigen-experienced effector memory versus naïve T cells in obese SAT may account in part for the metabolic differences described in obese humans. The present findings contribute to our understanding of the link between inflammatory cells and the development of IR. Previously, the majority of studies related to inflammation and IR focused on innate immunity, but recent studies in mice demonstrated an important role of $\mathrm{CD}^{+}$and $\mathrm{CD} 8^{+} \mathrm{T}$ cells in the development of $\mathrm{IR}(18,53,54)$. They have shown that cytotoxic $\mathrm{CD}^{+} \mathrm{T}$ cells and Treg cells play opposing roles in IR and WAT inflammation. In line with these findings, we previously observed that effector memory $\mathrm{CD}^{+} \mathrm{T}$ cells correlate significantly with glucose tolerance, measured via intraperitoneal glucose tolerance tests in high-fat diet fed mice (55). In conclusion, the present study supports the hypothesis that proinflammatory immune action in SAT plays an important role in determining IR.

While there is evidence that adaptive immunity is involved in the development of IR in mice, it is unclear if the accumulation of B and T cells in WAT is based on their antigen-specific activation or functions as a result of general inflammation. Importantly, some of the above mentioned studies showed severely biased T-cell repertoires in WAT $(53,56)$, suggesting intra-WAT antigen-specific responses of $\mathrm{T}$ cells. Hypertrophic adipocytes can become necrotic and release cellular components and secrete molecules, which could serve as potential (auto-)antigens. Stress proteins are also discussed as $\mathrm{T}$ cell targets. In contrast to these mice studies, no significant changes to the TCR repertoire were observed in a recently published human study using GeneScan analysis of Vß-Jß arrangements to compare lean versus non-diabetic obese subjects (43). In line with these findings, we found a polyclonal TCR- $\beta$ repertoire in SAT of obese probands using next generation sequencing.

457 Obesity has become one of the most serious health problems globally. Whereas it is not difficult to lose weight, only a small minority is able to maintain the reduced weight long-term. Surprisingly, we were unable to detect significant alterations in frequencies of leucocyte subsets investigated via flow cytometry or secretion of cytokines investigated via immunoassay after short-term CR induced weight loss. Consistently, it has been previously reported that mice with obesity experience displayed much faster body weight regain, while this obesity memory had a long-lasting effect and was mainly mediated by $\mathrm{CD}^{+} \mathrm{T}$ cells from previously obese mice (57). Additionally, previous mouse studies 
reported that weight fluctuation enhances inflammation due to persistent microbiome alterations in obese mice (58). These results suggest that $\mathrm{T}$ cells have a vital role in establishing obesity memory and might explain why short-term CR of obese probands often results in unavoidable weight regain.

Our study is limited by the relatively small number of obese subjects willing to undergo CR intervention as well as SAT biopsies and the inability to perform extensive flow cytometry on every tissue sample at all three intervention time points of the sub-study C. However, as we investigated a very specific sample, the relative homogeneity of our study participants (obese postmenopausal women) could strengthen the present study (small range in BMI and age is important due to agerelated changes in immune function). Nevertheless, future studies are needed to extend the findings to a broader population. Moreover, as is common in observational human studies, it is difficult to prove causality. However, considering the present findings and those from prior weight gain-loss obese mice studies (57), in which $\mathrm{CD} 4^{+} \mathrm{T}$ cells were shown to mediate obesity memory and promote weight regain, our results are highly suggestive of a similar relationship in humans. As the gut microbiota seems to be involved in the induction of obesity and interacts with the gut immune system (59), regulating the formation of effector memory T-cell subsets, studies investigating the modulation of the gut microbiome through diet, pre- and probiotics, antibiotics, surgery, and fecal transplantation are warranted. The modulation of the gut microbiome through CR-induced weight loss was investigated in another sub-study in our group (data submitted).

In summary, the present findings extend previous studies in mice and add to the limited reports in humans, implicating a role of T cells in obesity-related IR and T2D and providing evidence for a link between inflammation and IR in humans. Moreover, we provide new insight into the impact of CR on the inflammatory state in SAT. Collectively, these data indicate that the inflammatory signature in SAT of obese probands could not be reshaped by CR. Further investigation into specific $T$ lymphocyte subtypes and antigens involved in the mechanism of CR and weight regain, may help to develop more efficient anti-obesity strategies.

\section{Conflict of Interest}

The authors declare that the research was conducted in the absence of any commercial or financial relationships that could be construed as a potential conflict of interest.

\section{Author Contributions}

JS-K, H-DV and JS designed and planned the study. JK performed experiments supervised by JS-K. JS-K performed experiments, analysed and interpreted data. JS-K composed figures and JS-K, H-DV and JS wrote the manuscript. KM, RJvonS, A-MD and LS provided patient samples and data, MS provided help with flow cytometry analysis, LK and KJ performed bioinformatic analyses, UK helped with the sequencing devices and all authors approved the final version of the manuscript.

\section{Funding}

JS was supported by the DZHK (German Center for Cardiovascular Research), JS, KM and J-SK were supported by a clinical research group of the DFG (KFO218 and KFO192). This study was 
supported by grants from the Clinical Research Unit of the Berlin Institute of Health (BIH), the "BCRT-grant" by the German Federal Ministry of Education and Research and the Einstein Foundation. JSK and RJvonS were supported by the Charité Clinical Scientist Program.

\section{Acknowledgments}

We thank Francesca Liersch, Sarina Richter and Christiane Gras for excellent assistance with experimental procedures. We acknowledge the assistance of the BCRT Flow Cytometry Core Facility, Dr. D. Kunkel and Dr. Sarah Meier. We thank Catherine Steer for carefully reading the manuscript.

The raw data supporting the conclusions of this manuscript will be made available by the authors, without undue reservation, to any qualified researcher.

\section{References}

1. D. P. Guh, W. Zhang, N. Bansback, Z. Amarsi, C. L. Birmingham, A. H. Anis, The incidence of co-morbidities related to obesity and overweight: A systematic review and meta-analysis. BMC Public Health 9, 88 (2009).

2. L. Akil, H. A. Ahmad, Relationships between Obesity and Cardiovascular Diseases in Four Southern States and Colorado. J. Health Care Poor Underserved 22, 61-72 (2011).

3. J.-P. Després, I. Lemieux, Abdominal obesity and metabolic syndrome. Nature 444, 881 (2006).

4. E. E. Calle, R. Kaaks, Overweight, obesity and cancer: epidemiological evidence and proposed mechanisms. Nature Reviews Cancer 4, 579 (2004).

5. M. Ng, T. Fleming, M. Robinson, B. Thomson, N. Graetz, C. Margono, E. C. Mullany, S. Biryukov, C. Abbafati, S. F. Abera, J. P. Abraham, N. M. E. Abu-Rmeileh, T. Achoki, F. S. AlBuhairan, Z. A. Alemu, R. Alfonso, M. K. Ali, R. Ali, N. A. Guzman, W. Ammar, P. Anwari, A. Banerjee, S. Barquera, S. Basu, D. A. Bennett, Z. Bhutta, J. Blore, N. Cabral, I. C. Nonato, J.-C. Chang, R. Chowdhury, K. J. Courville, M. H. Criqui, D. K. Cundiff, K. C. Dabhadkar, L. Dandona, A. Davis, A. Dayama, S. D. Dharmaratne, E. L. Ding, A. M. Durrani, A. Esteghamati, F. Farzadfar, D. F. J. Fay, V. L. Feigin, A. Flaxman, M. H. Forouzanfar, A. Goto, M. A. Green, R. Gupta, N. Hafezi-Nejad, G. J. Hankey, H. C. Harewood, R. Havmoeller, S. Hay, L. Hernandez, A. Husseini, B. T. Idrisov, N. Ikeda, F. Islami, E. Jahangir, S. K. Jassal, S. H. Jee, M. Jeffreys, J. B. Jonas, E. K. Kabagambe, S. E. A. H. Khalifa, A. P. Kengne, Y. S. Khader, Y.-H. Khang, D. Kim, R. W. Kimokoti, J. M. Kinge, Y. Kokubo, S. Kosen, G. Kwan, T. Lai, M. Leinsalu, Y. Li, X. Liang, S. Liu, G. Logroscino, P. A. Lotufo, Y. Lu, J. Ma, N. K. Mainoo, G. A. Mensah, T. R. Merriman, A. H. Mokdad, J. Moschandreas, M. Naghavi, A. Naheed, D. Nand, K. M. V. Narayan, E. L. Nelson, M. L. Neuhouser, M. I. Nisar, T. Ohkubo, S. O. Oti, A. Pedroza, D. Prabhakaran, N. Roy, U. Sampson, H. Seo, S. G. Sepanlou, K. Shibuya, R. Shiri, I. Shiue, G. M. Singh, J. A. Singh, V. Skirbekk, N. J. C. Stapelberg, L. Sturua, B. L. Sykes, M. Tobias, B. X. Tran, L. Trasande, H. Toyoshima, S. van de Vijver, T. J. Vasankari, J. L. Veerman, G. VelasquezMelendez, V. V. Vlassov, S. E. Vollset, T. Vos, C. Wang, X. Wang, E. Weiderpass, A. 
Werdecker, J. L. Wright, Y. C. Yang, H. Yatsuya, J. Yoon, S.-J. Yoon, Y. Zhao, M. Zhou, S. Zhu, A. D. Lopez, C. J. L. Murray, E. Gakidou, Global, regional, and national prevalence of overweight and obesity in children and adults during 1980\&\#x2013;2013: a systematic analysis for the Global Burden of Disease Study 2013. The Lancet 384, 766-781.

6. $\quad$ M. Prentki, Islet $\beta$ cell failure in type 2 diabetes. 116, 1802-1812 (2006).

7. S. E. Shoelson, J. Lee, A. B. Goldfine, Inflammation and insulin resistance. J. Clin. Invest. 116, 1793-1801 (2006).

8. S. E. Kahn, R. L. Hull, K. M. Utzschneider, Mechanisms linking obesity to insulin resistance and type 2 diabetes. Nature 444, 840 (2006).

9. J. Spranger, A. Kroke, M. Möhlig, K. Hoffmann, M. M. Bergmann, M. Ristow, H. Boeing, A. F. H. Pfeiffer, Inflammatory Cytokines and the Risk to Develop Type 2 Diabetes. Results of the Prospective Population-Based European Prospective Investigation into Cancer and Nutrition (EPIC)-Potsdam Study 52, 812-817 (2003).

10. M. A. Exley, L. Hand, D. O'Shea, L. Lynch, Interplay between the immune system and adipose tissue in obesity. J. Endocrinol. 223, R41-R48 (2014).

11. A. W. Ferrante, The Immune Cells in Adipose Tissue. Diabetes Obes. Metab. 15, 34-38 (2013).

12. Joanne C. McNelis, Jerrold M. Olefsky, Macrophages, Immunity, and Metabolic Disease. Immunity 41, 36-48.

13. A. W. Ferrante, Macrophages, fat, and the emergence of immunometabolism. J. Clin. Invest. 123, 4992-4993 (2013).

14. F. O. Martinez, S. Gordon, The M1 and M2 paradigm of macrophage activation: time for reassessment. F1000Prime Rep 6, (2014).

15. J. Liu, A. Divoux, J. Sun, J. Zhang, K. Clément, J. N. Glickman, G. K. Sukhova, P. J. Wolters, J. Du, C. Z. Gorgun, A. Doria, P. Libby, R. S. Blumberg, B. B. Kahn, G. S. Hotamisligil, G.-P. Shi, Genetic deficiency and pharmacological stabilization of mast cells reduce diet-induced obesity and diabetes in mice. Nat. Med. 15, 940 (2009).

16. S. Talukdar, D. Y. Oh, G. Bandyopadhyay, D. Li, J. Xu, J. McNelis, M. Lu, P. Li, Q. Yan, Y. Zhu, J. Ofrecio, M. Lin, M. B. Brenner, J. M. Olefsky, Neutrophils mediate insulin resistance in high fat diet fed mice via secreted elastase. Nat. Med. 18, 1407-1412 (2012).

17. M. Stefanovic-Racic, X. Yang, M. S. Turner, B. S. Mantell, D. B. Stolz, T. L. Sumpter, I. J. Sipula, N. Dedousis, D. K. Scott, P. A. Morel, A. W. Thomson, R. M. O’Doherty, Dendritic Cells Promote Macrophage Infiltration and Comprise a Substantial Proportion of ObesityAssociated Increases in CD11 ${ }^{+}$Cells in Adipose Tissue and Liver. Diabetes 61, 2330-2339 (2012).

18. S. Nishimura, I. Manabe, M. Nagasaki, K. Eto, H. Yamashita, M. Ohsugi, M. Otsu, K. Hara, K. Ueki, S. Sugiura, K. Yoshimura, T. Kadowaki, R. Nagai, CD8+ effector T cells contribute to macrophage recruitment and adipose tissue inflammation in obesity. Nat. Med. 15, 914-920 (2009).

19. D. A. Winer, S. Winer, L. Shen, P. P. Wadia, J. Yantha, G. Paltser, H. Tsui, P. Wu, M. G. Davidson, M. N. Alonso, H. X. Leong, A. Glassford, M. Caimol, J. A. Kenkel, T. F. Tedder, T. McLaughlin, D. B. Miklos, H. M. Dosch, E. G. Engleman, B cells promote insulin 
resistance through modulation of $\mathrm{T}$ cells and production of pathogenic IgG antibodies. Nat. Med. 17, 610 (2011).

20. T. Onodera, A. Fukuhara, M. H. Jang, J. Shin, K. Aoi, J. Kikuta, M. Otsuki, M. Ishii, I. Shimomura, Adipose tissue macrophages induce PPAR $\gamma$-high FOXP3(+) regulatory T cells. Sci. Rep. 5, (2015).

21. R. Zhao, D. Tang, S. Yi, W. Li, C. Wu, Y. Lu, X. Hou, J. Song, P. Lin, L. Chen, L. Sun, Elevated Peripheral Frequencies of Th22 Cells: A Novel Potent Participant in Obesity and Type 2 Diabetes. PLoS One 9, e85770 (2014).

22. N.-M. Wagner, G. Brandhorst, F. Czepluch, M. Lankeit, C. Eberle, S. Herzberg, V. Faustin, J. Riggert, M. Oellerich, G. Hasenfuss, S. Konstantinides, K. Schäfer, Circulating regulatory T cells are reduced in obesity and may identify subjects at increased metabolic and cardiovascular risk. Obesity 21, 461-468 (2013).

23. H. Wu, S. Ghosh, X. D. Perrard, L. Feng, G. E. Garcia, J. L. Perrard, J. F. Sweeney, L. E. Peterson, L. Chan, C. W. Smith, C. M. Ballantyne, T-Cell Accumulation and Regulated on Activation, Normal T Cell Expressed and Secreted Upregulation in Adipose Tissue in Obesity. Circulation 115, 1029-1038 (2007).

24. E. Fabbrini, M. Cella, S. A. McCartney, A. Fuchs, N. A. Abumrad, T. A. Pietka, Z. Chen, B. N. Finck, D. H. Han, F. Magkos, C. Conte, D. Bradley, G. Fraterrigo, J. C. Eagon, B. W. Patterson, M. Colonna, S. Klein, Association Between Specific Adipose Tissue CD4 ${ }^{+}$T-Cell Populations and Insulin Resistance in Obese Individuals. Gastroenterology 145, 366374.e363.

25. T. McLaughlin, A. Deng, G. Yee, C. Lamendola, G. Reaven, P. S. Tsao, S. W. Cushman, A. Sherman, Inflammation in subcutaneous adipose tissue: relationship to adipose cell size. Diabetologia 53, 369 (2009).

26. J. Hellmann, B. E. Sansbury, C. R. Holden, Y. Tang, B. Wong, M. Wysoczynski, J. Rodriguez, A. Bhatnagar, B. G. Hill, M. Spite, CCR7 Maintains Nonresolving Lymph Node and Adipose Inflammation in Obesity. Diabetes 65, 2268-2281 (2016).

27. T. McLaughlin, L.-F. Liu, C. Lamendola, L. Shen, J. Morton, H. Rivas, D. Winer, L. Tolentino, O. Choi, H. Zhang, M. Hui Yen Chng, E. Engleman, <span hwp:id="article-title1" class="article-title" $>$ T-Cell Profile in Adipose Tissue Is Associated With Insulin Resistance and Systemic Inflammation in Humans</span><span hwp:id="article-title-25" class $="$ sub-article-title" $>$ Significance $</$ span $>$. Arterioscler. Thromb. Vasc. Biol. 34, 26372643 (2014).

28. R. M. Anderson, R. Weindruch, Metabolic reprogramming, caloric restriction and aging. Trends Endocrinol. Metab. 21, 134-141 (2010).

29. K. Dorshkind, E. Montecino-Rodriguez, R. A. J. Signer, The ageing immune system: is it ever too old to become young again? Nature Reviews Immunology 9, 57 (2009).

30. M. J. White, C. M. Beaver, M. R. Goodier, C. Bottomley, C. M. Nielsen, A. Wolf, L. Boldrin, C. Whitmore, J. Morgan, D. J. Pearce, E. M. Riley, Calorie Restriction Attenuates Terminal Differentiation of Immune Cells. Front. Immunol. 7, (2016).

31. F. Wasinski, R. F. P. Bacurau, M. R. Moraes, A. S. Haro, P. M. M. Moraes-Vieira, G. R. Estrela, E. J. Paredes-Gamero, C. C. Barros, S. S. Almeida, N. O. S. Câmara, R. C. Araujo, 
Exercise and Caloric Restriction Alter the Immune System of Mice Submitted to a High-Fat Diet. Mediators Inflamm. 2013, (2013).

32. J. Wang, S. M. Vanegas, X. Du, T. Noble, J. M. A. Zingg, M. Meydani, S. N. Meydani, D. $\mathrm{Wu}$, Caloric restriction favorably impacts metabolic and immune/inflammatory profiles in obese mice but curcumin/piperine consumption adds no further benefit. Nutr. Metab. (Lond.) 10, 29 (2013).

33. D. Tang, S. Tao, Z. Chen, I. O. Koliesnik, P. G. Calmes, V. Hoerr, B. Han, N. Gebert, M. Zörnig, B. Löffler, Y. Morita, K. L. Rudolph, Dietary restriction improves repopulation but impairs lymphoid differentiation capacity of hematopoietic stem cells in early aging. The Journal of Experimental Medicine, (2016).

34. T. Ahmed, S. K. Das, J. K. Golden, E. Saltzman, S. B. Roberts, S. N. Meydani, Calorie Restriction Enhances T-Cell-Mediated Immune Response in Adult Overweight Men and Women. J. Gerontol. A Biol. Sci. Med. Sci. 64a, 1107-1113 (2009).

35. S. N. Meydani, S. K. Das, C. F. Pieper, M. R. Lewis, S. Klein, V. D. Dixit, A. K. Gupta, D. T. Villareal, M. Bhapkar, M. Huang, P. J. Fuss, S. B. Roberts, J. O. Holloszy, L. Fontana, Longterm moderate calorie restriction inhibits inflammation without impairing cell-mediated immunity: a randomized controlled trial in non-obese humans. Aging (Albany NY) 8, 14161426 (2016).

36. A. J. Tomiyama, J. M. Milush, J. Lin, J. M. Flynn, P. Kapahi, E. Verdin, E. Sinclair, S. Melov, E. S. Epel, Long-term calorie restriction in humans is not associated with indices of delayed immunologic aging: A descriptive study. Nutr Healthy Aging 4, 147-156.

37. E. Ortega Martinez de Victoria, X. Xu, J. Koska, A. M. Francisco, M. Scalise, A. W. Ferrante, Jr., J. Krakoff, Macrophage content in subcutaneous adipose tissue: associations with adiposity, age, inflammatory markers, and whole-body insulin action in healthy Pima Indians. Diabetes 58, 385-393 (2009).

38. K. Mai, T. Bobbert, V. Kullmann, J. Andres, V. Bähr, C. Maser-Gluth, H. Rochlitz, J. Spranger, S. Diederich, A. F. H. Pfeiffer, No effect of free fatty acids on adrenocorticotropin and cortisol secretion in healthy young men. Metabolism - Clinical and Experimental 55, 1022-1028.

39. K. Mai, J. Andres, K. Biedasek, J. Weicht, T. Bobbert, M. Sabath, S. Meinus, F. Reinecke, M. Möhlig, M. O. Weickert, M. Clemenz, A. F. H. Pfeiffer, U. Kintscher, S. Spuler, J. Spranger, Free Fatty Acids Link Metabolism and Regulation of the Insulin-Sensitizing Fibroblast Growth Factor-21. Diabetes 58, 1532-1538 (2009).

40. M. Streitz, T. Miloud, M. Kapinsky, M. R. Reed, R. Magari, E. K. Geissler, J. A. Hutchinson, K. Vogt, S. Schlickeiser, A. H. Kverneland, C. Meisel, H.-D. Volk, B. Sawitzki, Standardization of whole blood immune phenotype monitoring for clinical trials: panels and methods from the ONE study. Transplantation Research 2, 17-17 (2013).

41. L. Amini, T. Vollmer, D. J. Wendering, A. Jurisch, S. Landwehr-Kenzel, N. M. Otto, K. Jürchott, H.-D. Volk, P. Reinke, M. Schmueck-Henneresse, Comprehensive Characterization of a Next-Generation Antiviral T-Cell Product and Feasibility for Application in Immunosuppressed Transplant Patients. Front. Immunol. 10, (2019).

42. L. Kuchenbecker, M. Nienen, J. Hecht, A. U. Neumann, N. Babel, K. Reinert, P. N. Robinson, IMSEQ - a fast and error aware approach to immunogenetic sequence analysis. (Bioinformatics September 15, 2015 31(18):2963). 
684

685

686

687

688

689

690

691

692

693

694

695

696

697

698

699

700

701

702

703

704

705

706

707

708

709

710

711

712

713

714

715

716

43. K. van der Weerd, W. A. Dik, B. Schrijver, D. H. Schweitzer, A. W. Langerak, H. A. Drexhage, R. M. Kiewiet, M. O. van Aken, A. van Huisstede, J. J. M. van Dongen, A.-J. van der Lelij, F. J. T. Staal, P. M. van Hagen, Morbidly Obese Human Subjects Have Increased Peripheral Blood $\mathrm{CD}^{+} \mathrm{T}$ Cells With Skewing Toward a Treg- and Th2-Dominated Phenotype. Diabetes 61, 401-408 (2012).

44. T. McLaughlin, L.-F. Liu, C. Lamendola, L. Shen, J. Morton, H. Rivas, D. Winer, L. Tolentino, O. Choi, H. Zhang, M. H. Y. Chng, E. Engleman, T-Cell Profile in Adipose Tissue Is Associated With Insulin Resistance and Systemic Inflammation in Humans. Arterioscler. Thromb. Vasc. Biol. 34, 2637-2643 (2014).

45. U. Kintscher, M. Hartge, K. Hess, A. Foryst-Ludwig, M. Clemenz, M. Wabitsch, P. FischerPosovszky, F. E. Barth Thomas, D. Dragun, T. Skurk, H. Hauner, M. Blüher, T. Unger, A.-M. Wolf, U. Knippschild, V. Hombach, N. Marx, T-lymphocyte Infiltration in Visceral Adipose Tissue. Arterioscler. Thromb. Vasc. Biol. 28, 1304-1310 (2008).

46. E. Dalmas, N. Venteclef, C. Caer, C. Poitou, I. Cremer, J. Aron-Wisnewsky, S. LacroixDesmazes, J. Bayry, S. V. Kaveri, K. Clément, S. André, M. Guerre-Millo, T Cell-Derived IL-22 Amplifies IL-1 $\beta$-Driven Inflammation in Human Adipose Tissue: Relevance to Obesity and Type 2 Diabetes. Diabetes 63, 1966-1977 (2014).

47. X. Yu, J. R. Almeida, S. Darko, M. van der Burg, S. S. DeRavin, H. Malech, A. Gennery, I. Chinn, M. L. Markert, D. C. Douek, J. D. Milner, Human syndromes of immunodeficiency and dysregulation are characterized by distinct defects in T-cell receptor repertoire development. The Journal of allergy and clinical immunology 133, 1109-1115 (2014).

48. K. Makki, P. Froguel, I. Wolowczuk, Adipose Tissue in Obesity-Related Inflammation and Insulin Resistance: Cells, Cytokines, and Chemokines. ISRN Inflamm 2013, (2013).

49. Cloning and characterization of a cDNA for murine macrophage inflammatory protein (MIP), a novel monokine with inflammatory and chemokinetic properties [published erratum appears in J Exp Med 1989 Dec 1;170(6):2189]. J. Exp. Med. 167, 1939-1944 (1988).

50. A. Bertola, T. Ciucci, D. Rousseau, V. Bourlier, C. Duffaut, S. Bonnafous, C. Blin-Wakkach, R. Anty, A. Iannelli, J. Gugenheim, A. Tran, A. Bouloumié, P. Gual, A. Wakkach, Identification of Adipose Tissue Dendritic Cells Correlated With Obesity-Associated InsulinResistance and Inducing Th17 Responses in Mice and Patients. Diabetes 61, 2238-2247 (2012).

51. R. L. Travers, A. C. Motta, J. A. Betts, A. Bouloumié, D. Thompson, The impact of adiposity on adipose tissue-resident lymphocyte activation in humans. Int. J. Obes. 39, 762 (2014).

52. K. Wouters, K. Gaens, M. Bijnen, K. Verboven, J. Jocken, S. Wetzels, E. Wijnands, D. Hansen, M. van Greevenbroek, A. Duijvestijn, E. A. L. Biessen, E. E. Blaak, C. D. A. Stehouwer, C. G. Schalkwijk, Circulating classical monocytes are associated with CD11c+ macrophages in human visceral adipose tissue. Sci. Rep. 7, 42665 (2017).

53. S. Winer, Y. Chan, G. Paltser, D. Truong, H. Tsui, J. Bahrami, R. Dorfman, Y. Wang, J. Zielenski, F. Mastronardi, Y. Maezawa, D. Drucker, E. Engleman, D. Winer, H. M. Dosch, Normalization of Obesity-Associated Insulin Resistance through Immunotherapy: CD4+ T Cells Control Glucose Homeostasis. Nat. Med. 15, 921-929 (2009).

54. K. A. Harford, C. M. Reynolds, F. C. McGillicuddy, H. M. Roche, Fats, inflammation and insulin resistance: insights to the role of macrophage and T-cell accumulation in adipose tissue. Proc. Nutr. Soc. 70, 408-417 (2011). 
732

733

734

\section{5}

736

737

738

739

740

741

742

743

744

745

746

747

748

749

750

751

752

753

754

755

756

757

758

759
55. J. Sbierski-Kind, J. Kath, S. Brachs, M. Streitz, M. G. von Herrath, A. A. Kühl, K. SchmidtBleek, K. Mai, J. Spranger, H.-D. Volk, Distinct Housing Conditions Reveal a Major Impact of Adaptive Immunity on the Course of Obesity-Induced Type 2 Diabetes. Front. Immunol. 9, (2018).

56. M. Feuerer, L. Herrero, D. Cipolletta, A. Naaz, J. Wong, A. Nayer, J. Lee, A. B. Goldfine, C. Benoist, S. Shoelson, D. Mathis, Lean, but not obese, fat is enriched for a unique population of regulatory T cells that affect metabolic parameters. Nat. Med. 15, 930 (2009).

57. J. Zou, B. Lai, M. Zheng, Q. Chen, S. Jiang, A. Song, Z. Huang, P. Shi, X. Tu, D. Wang, L. Lu, Z. Lin, X. Gao, CD4+ T cells memorize obesity and promote weight regain. Cellular And Molecular Immunology, (2017).

58. C. A. Thaiss, S. Itav, D. Rothschild, M. T. Meijer, M. Levy, C. Moresi, L. Dohnalová, S. Braverman, S. Rozin, S. Malitsky, M. Dori-Bachash, Y. Kuperman, I. Biton, A. Gertler, A. Harmelin, H. Shapiro, Z. Halpern, A. Aharoni, E. Segal, E. Elinav, Persistent microbiome alterations modulate the rate of post-dieting weight regain. Nature 540, 544 (2016).

59. P. J. Turnbaugh, F. Bäckhed, L. Fulton, J. I. Gordon, Diet-Induced Obesity Is Linked to Marked but Reversible Alterations in the Mouse Distal Gut Microbiome. Cell Host \& Microbe 3, 213-223.

\section{Figure Legends}

Figure 1. (A) Study design: Obese postmenopausal women randomized into two groups (CR group and control group) underwent baseline measurements and follow-up measurements including medical examination and metabolic phenotyping. Between M0 and M3 (after 12 weeks), participants in the CR group lost more than $10 \%$ of their body weight following CR. Weight loss was induced by a lowcaloric formula diet ( $800 \mathrm{kcal} / \mathrm{day}$ ) in the first 8 weeks. Between M3 and M4 (after additional 4 weeks), participants in the CR group followed an isocaloric diet without having a negative energy balance. Participants in the control group were instructed not to change their dietary habits. (B) BMI changes of participants of the sub-study $\mathrm{C}$ are shown and are representative for the other sub-studies. A repeated measurement 2 way ANOVA followed by SIDAK correction testing for group $\mathrm{x}$ time interactions indicated significant weight loss in the CR group (**** $P<0.0001)$ between M0 and M3. Participants in the CR group were able to maintain reduced weight until M4 (no significant difference in BMI between M3 and M4). $n=6$ per group.

Figure 2. Altered immune cell composition in peripheral blood in overweight/obese vs. lean probands. PBMCs isolated from venous blood of overweight/obese $(n=21)$ and lean $(n=16)$ age and sex-matched probands were analyzed with multiparameter flow cytometry at time point 0 (M0). (A) No differences among absolute major leukocyte subset counts were observed. (B, C). Proportions of $\mathrm{CD}^{+}$and $\mathrm{CD} 8^{+} \mathrm{T}$ cells and absolute cell counts of $\mathrm{CD}^{+}$and $\mathrm{CD}^{+}$naïve $\left(\mathrm{T}_{\text {naïve }}\right)$, central memory $\left(\mathrm{T}_{\mathrm{CM}}\right)$, effector memory $\left(\mathrm{T}_{\mathrm{EM}}\right)$ and terminally differentiated effector memory $\mathrm{T}$ cells $\left(\mathrm{T}_{\mathrm{EMRA}}\right)$ determined from flow cytometric data. An increase in $T_{\text {naïve }}$ but decrease in $T_{E M}$ was observed for both percentages of $\mathrm{CD}^{+}$and $\mathrm{CD}^{+} \mathrm{T}$ cells and absolute cell counts in overweight/obese compared to lean probands. (D) Absolute cell counts of B cells showed an increase of naïve B cells in overweight/obese compared to lean probands. For all graphs data points were tested with repeated measurement 2 way ANOVA followed by SIDAK correction. $P$-values below 0.05 are indicated by * and defined to be significant. 
Figure 3. Altered composition of immune cell subsets in obesity is correlated with the BMI. PBMCs isolated from venous blood of overweight/obese $(n=21)$ and lean $(n=16)$ age and sexmatched probands were analyzed with multiparameter flow cytometry at time point 0 (M0) and resulting immune cell parameters were correlated with metabolic measures. (A-K) Positive correlations between peripheral blood leukocyte counts $(\mathbf{A})$, activated monocytes $\left(\mathrm{CD} 14^{+} \mathrm{CD} 16^{\text {high }}\right)$ (B), naïve $\mathrm{CD}^{+}(\mathbf{C})$, early central memory $\mathrm{CD}^{+}(\mathbf{D})$, naïve $\mathrm{CD}^{+}(\mathbf{E})$, early central memory $\mathrm{CD} 8^{+}$ (F) T-cell subsets and the BMI. Negative correlations between leucocyte and monocyte cell counts with $\operatorname{ISI}_{\text {Clamp }}(\mathbf{G}, \mathbf{H})$. Positive correlation between the percentage of B cells (I), naïve CD8 ${ }^{+} \mathrm{T}$ cells (J) and non-classical Th1 CD4 ${ }^{+} \mathrm{T}$ cells $(\mathbf{K})$ and ISI $_{\text {Clamp. Black dots represent study probands (obese }}$ $n=21$, lean $n=16)$. Spearman's and Pearson's correlation analysis was conducted.

Figure 4. Influence of obesity on different $T$ cell memory subsets in human SAT. SAT immune cells from overweight/obese age and sex-matched probands $(n=21)$ were isolated and analyzed with multiparameter flow cytometry at time point 0 (M0). Total cell counts and percentages were compared between peripheral blood and SAT. (A-C) Leucocyte and T cell subpopulations in blood and SAT of obese probands. (D) Representative dot plots of $\mathrm{CD}^{+}$and $\mathrm{CD} 8^{+} \mathrm{T}$ cell subsets in blood and SAT of obese probands. (E, F) Correlations between $\mathrm{CD} 8^{+} \mathrm{T}$ cell subsets with the ISI $_{\text {Clamp. }} * * * \mathrm{P}$ $<0.001 * * * * \mathrm{P}<0.0001$ Spearman's correlation analysis was conducted.

Figure 5. TCR clonal expansion and diversity of TCR repertoire in SAT and blood of obese patients. (A) The diversity of the TCR repertoire from peripheral blood and SAT from obese patients $(n=20)$ from sub-study B. The mean and standard deviation for the entropy value when sampling the same number of sequences from the blood repertoire as obtained from the SAT repertoire. The difference between the observed entropy in the SAT samples and the mean entropy from sampled repertoires is provided in the last column. (B) Frequencies among productive rearrangements of the top100 clones of SAT (orange) and Blood (black) of 3 overweight/obese probands. ** $\mathrm{P}<0.01$. Comparison between blood and SAT samples were tested by Wilcoxon signed-rank test.

786

Figure 6. Leucocyte numbers and cytokine levels in SAT are not altered after CR. (A) Systemic leucocyte cell numbers at time points 0 (M0, starting point), 3 (M3) and 4 (M4) in overweight/obese probands $(\mathrm{n}=22)$ of the control (black dots) and CR group (white dots). (B-J) SAT levels of IL-6, IL13, IL-7, IL-8, MIP-1a, MIP-1b, MIP-3a, ITAC and Fractalkine in probands of the control and CR group. (K) Correlation of BMI with MIP-1a levels in SAT of probands of the control and CR group. (L) Correlation of ISI $_{\text {Clamp }}$ with MIP-3a levels in SAT of probands of the control and CR group. Spearman's correlation analysis was conducted. $P$-values below 0.05 are indicated by $*$ and defined to be significant.

Table 1. Metabolic and anthropometric parameters of the randomized participants before CRinduced weight loss. The results are presented as mean $\square \pm \square$ standard deviation (SD). One-Way ANOVA was conducted and P-values below 0.05 are defined to be significant.

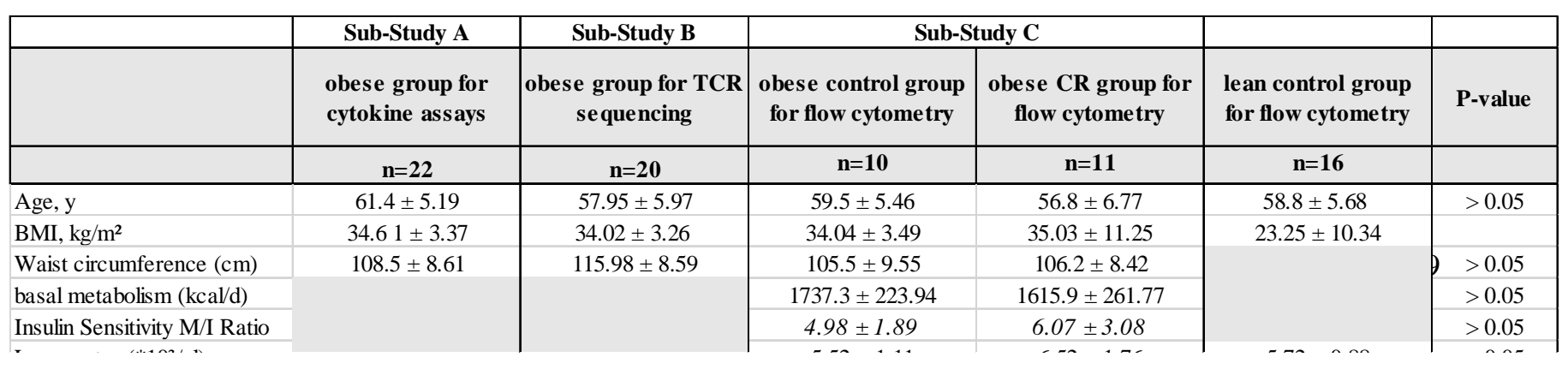


medRxiv preprint doi: https://doi.org/10.1101/19005934; this version posted September 9, 2019. The copyright holder for this preprint (which was not certified by peer review) is the author/funder, who has granted medRxiv a license to display the preprint in perpetuity.

All rights reserved. No ${ }^{\text {reffse }}$ elllowod without permission.

798 


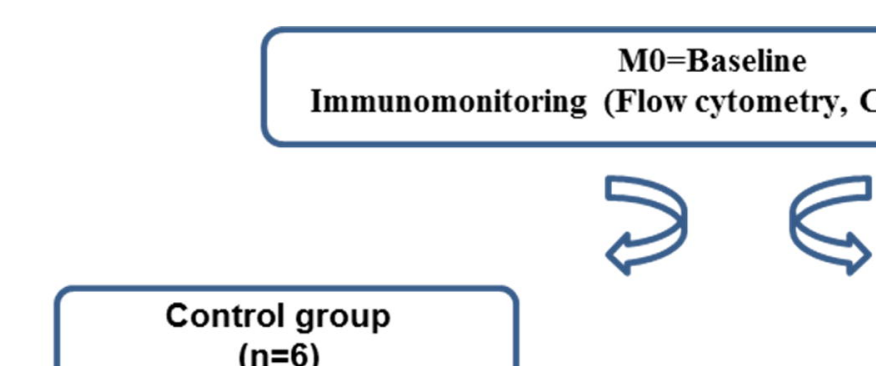

$(n=6)$

Intervention group

$$
(n=5)
$$

Maintaining weight stable

M3=Follow-up after 3 months

Immunomonitoring (Flow cytometry, Cytokine Assays)
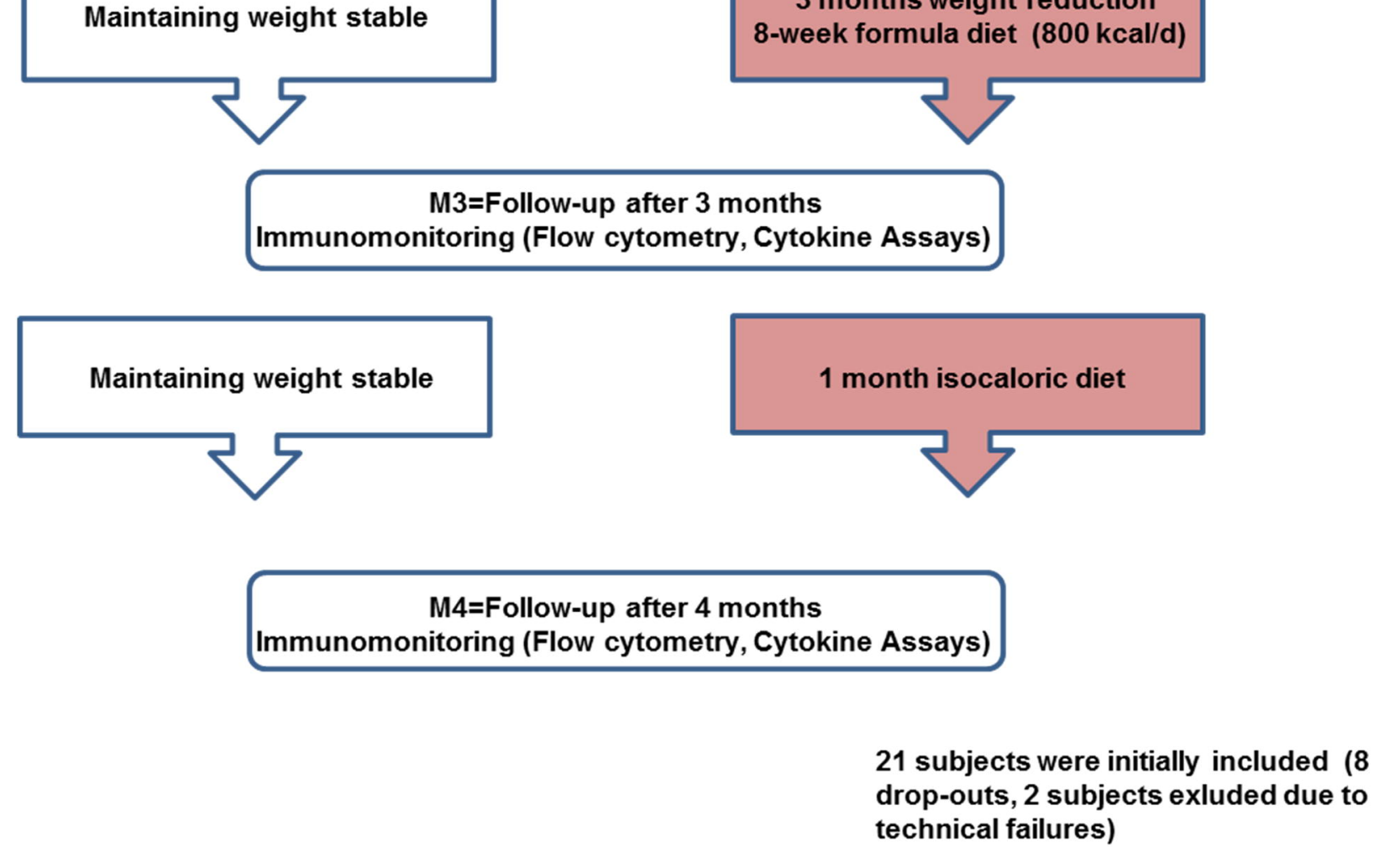

M4=Follow-up after 4 months

Immunomonitoring (Flow cytometry, Cytokine Assays)

21 subjects were initially included $(8$
drop-outs, 2 subjects exluded due to technical failures)

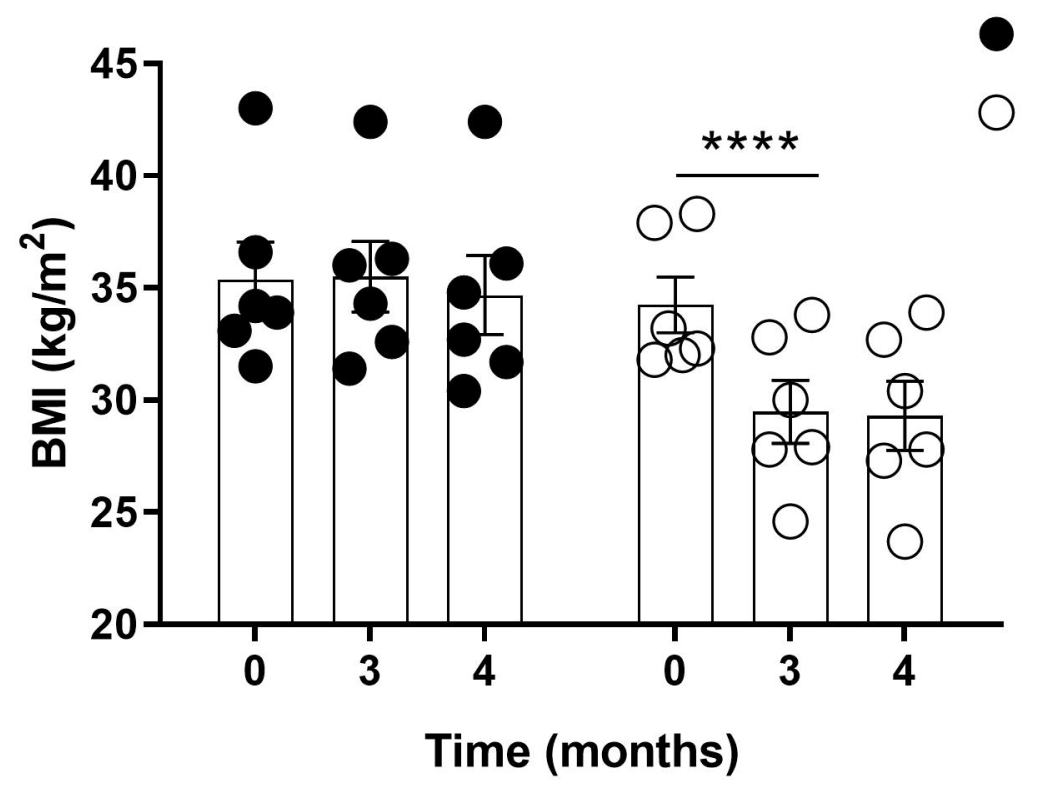

- control group

CR group 
A

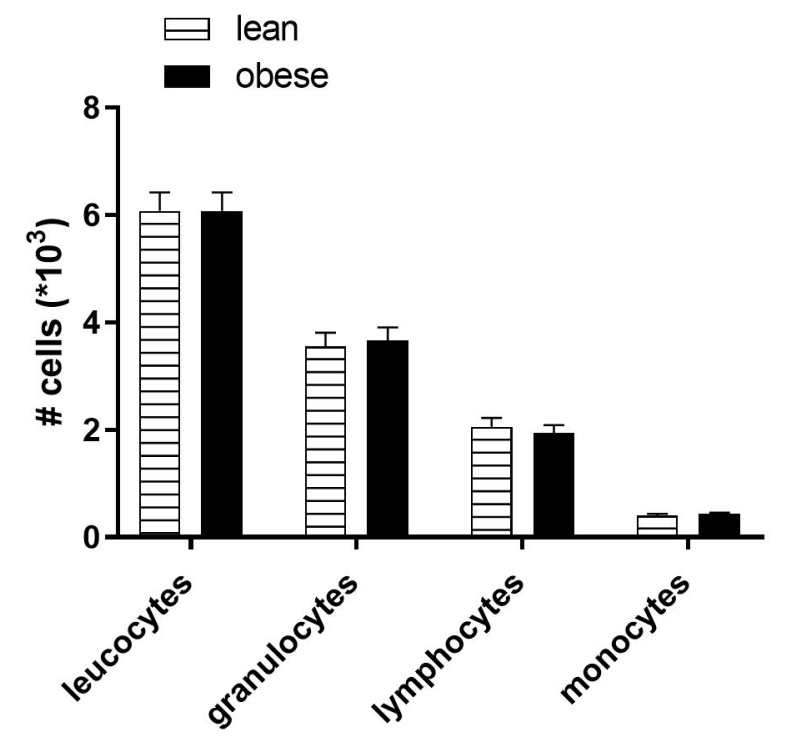

D

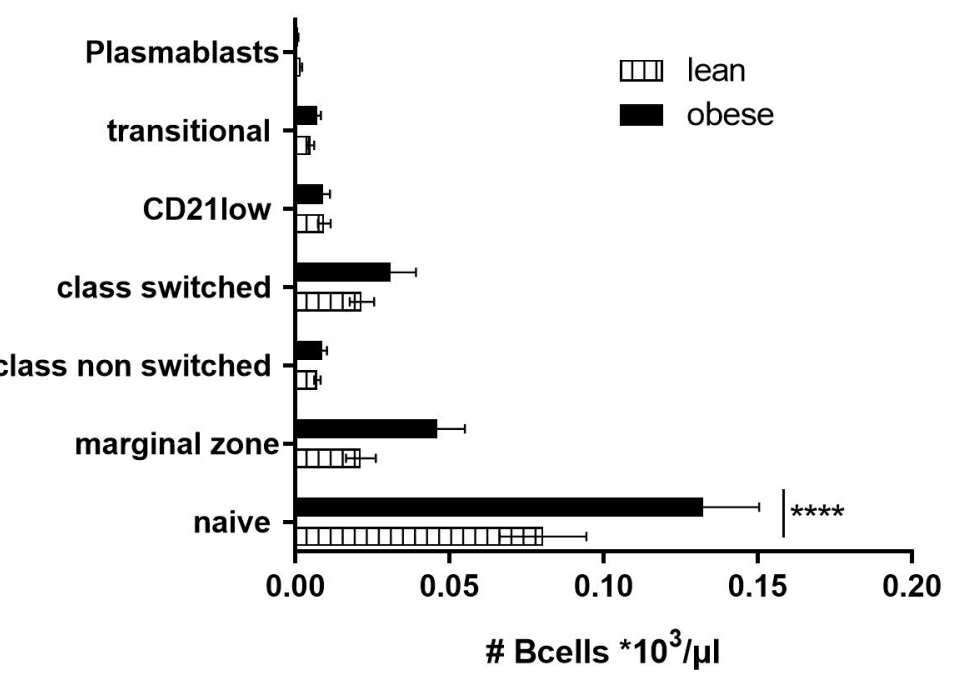

B
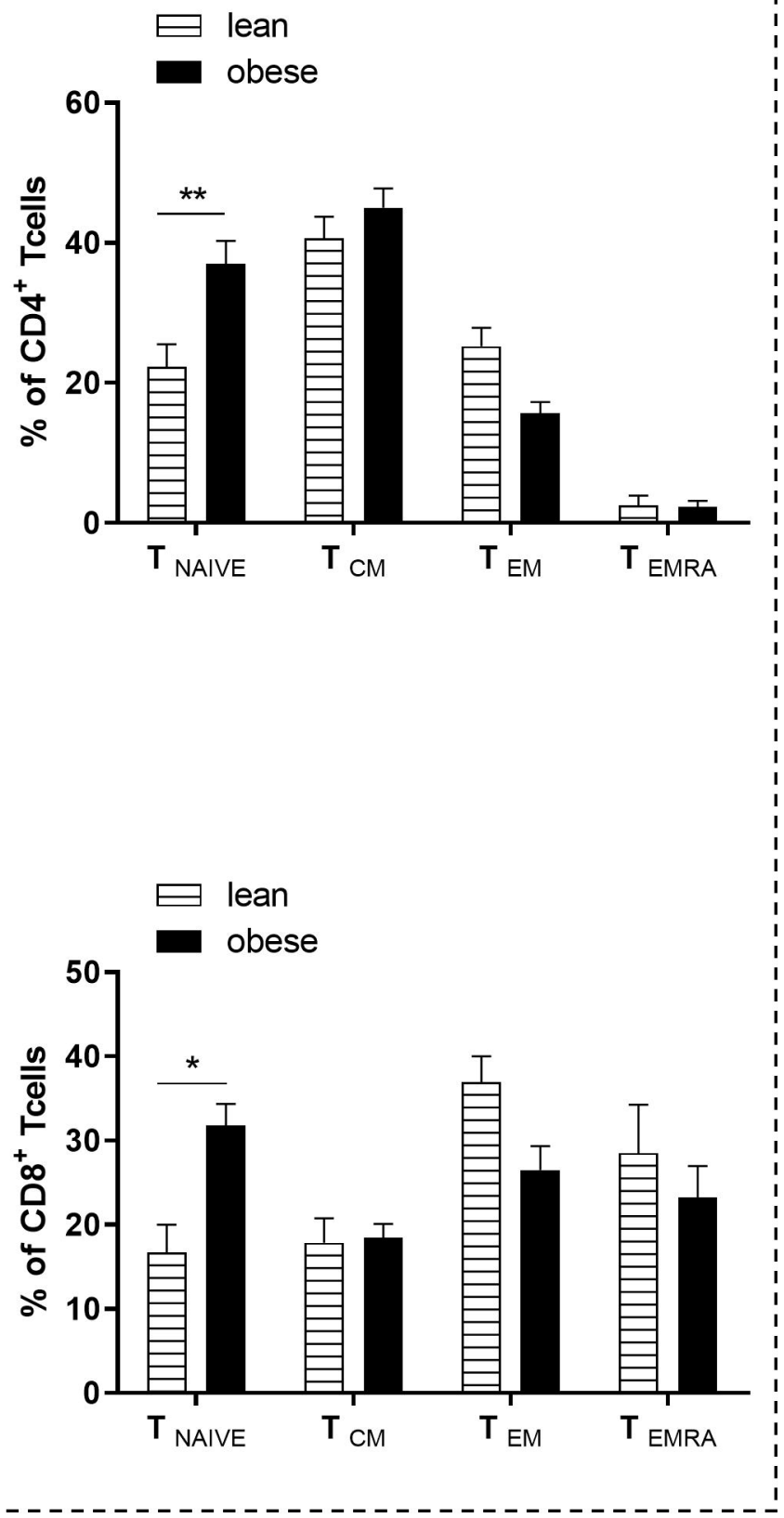

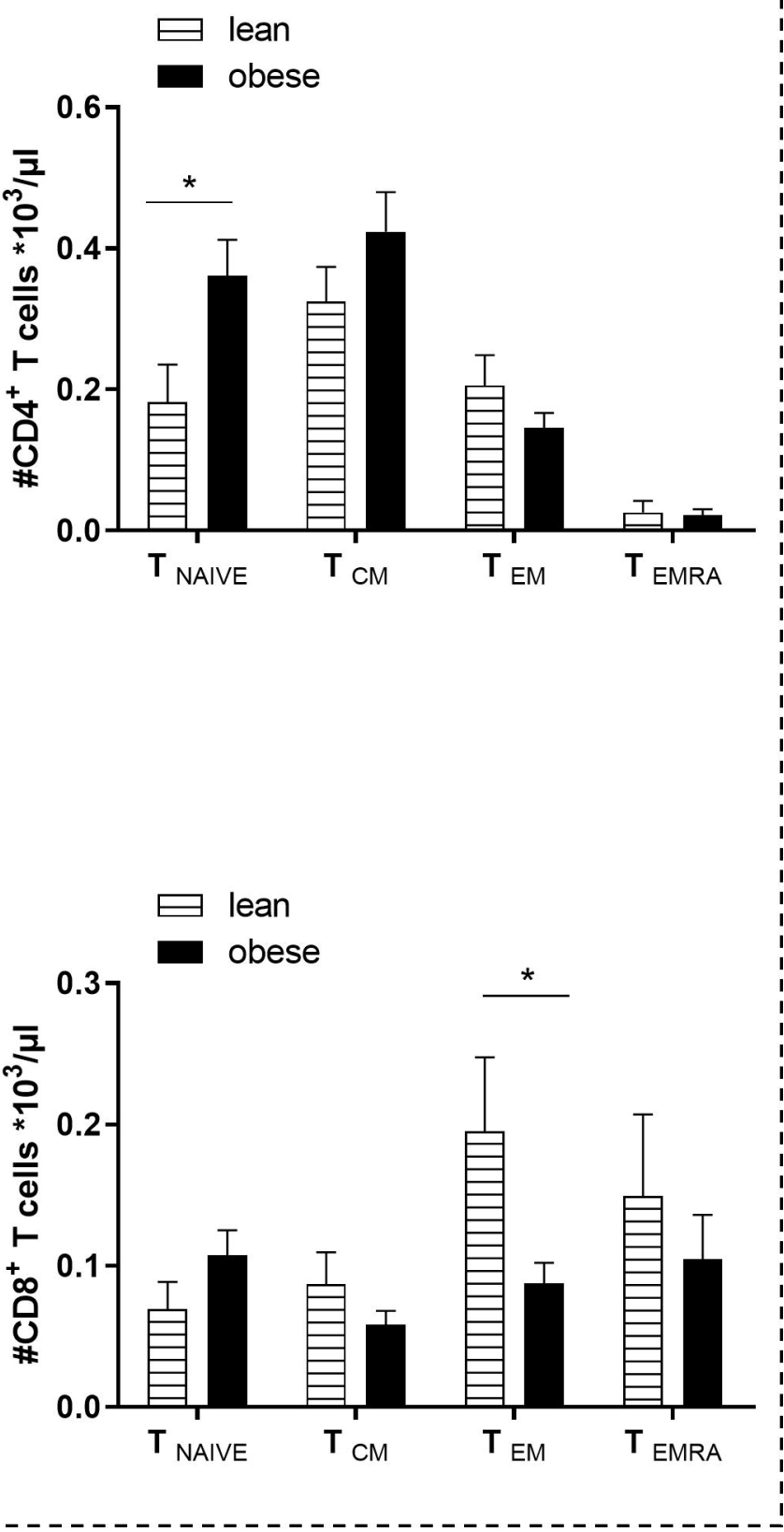


A
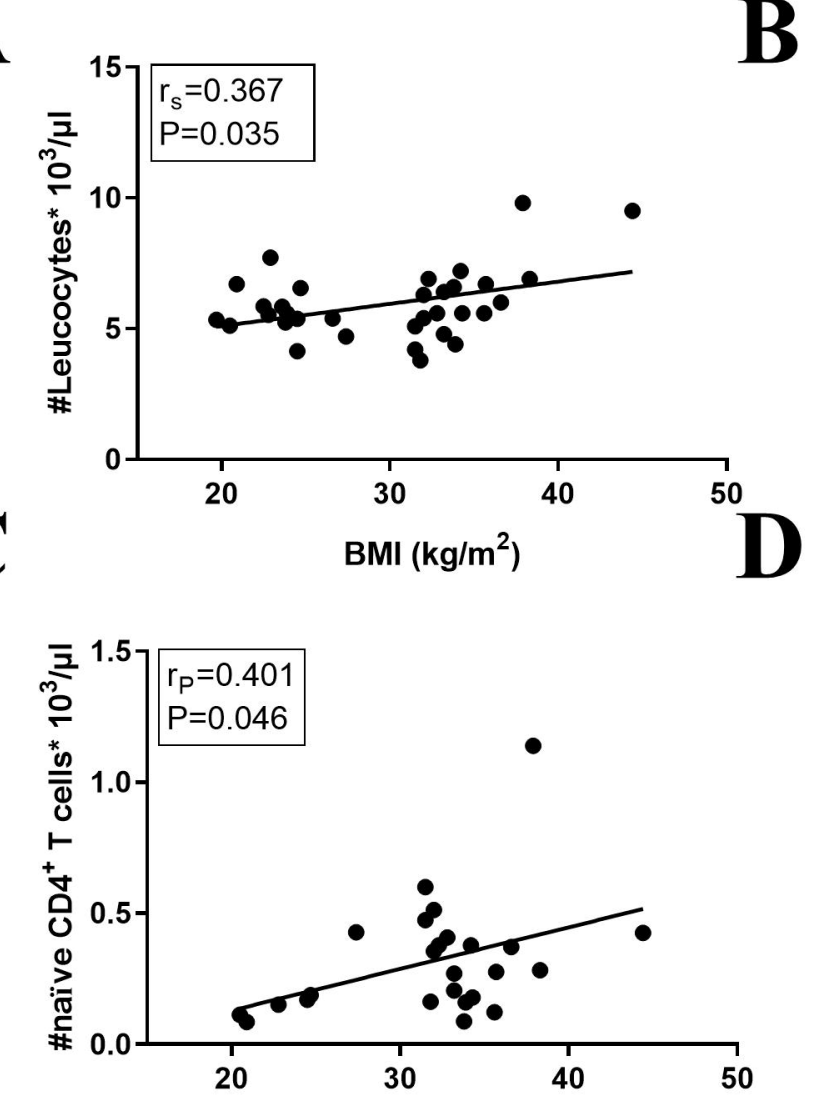

E

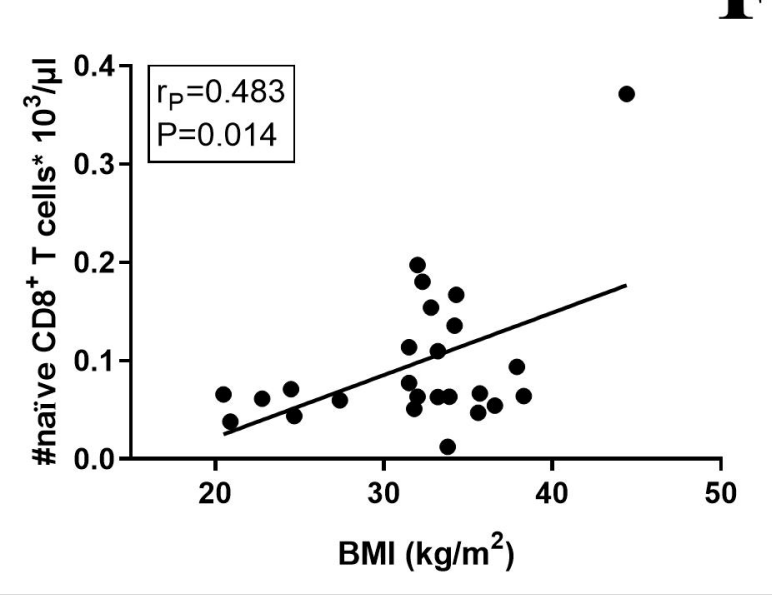

F
G
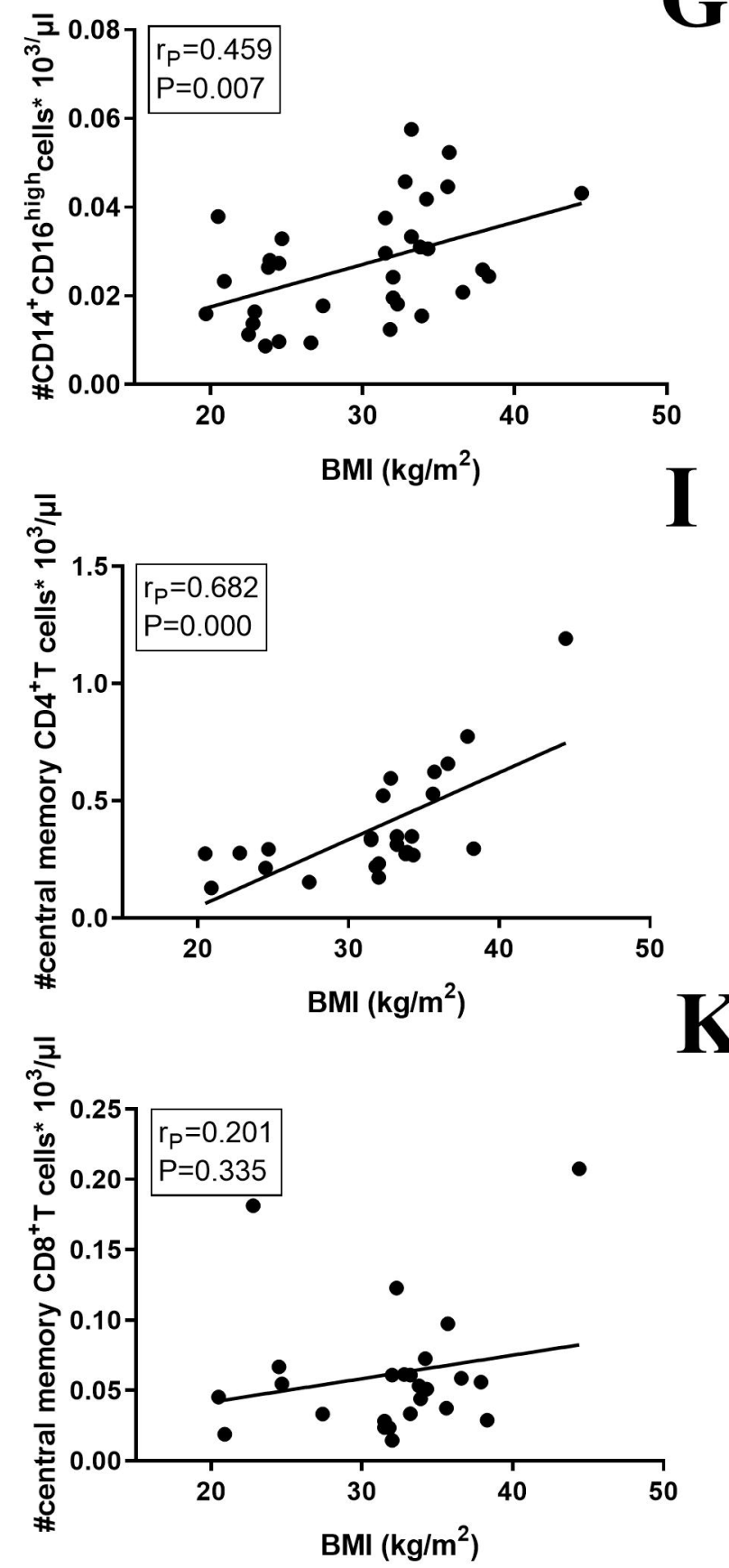
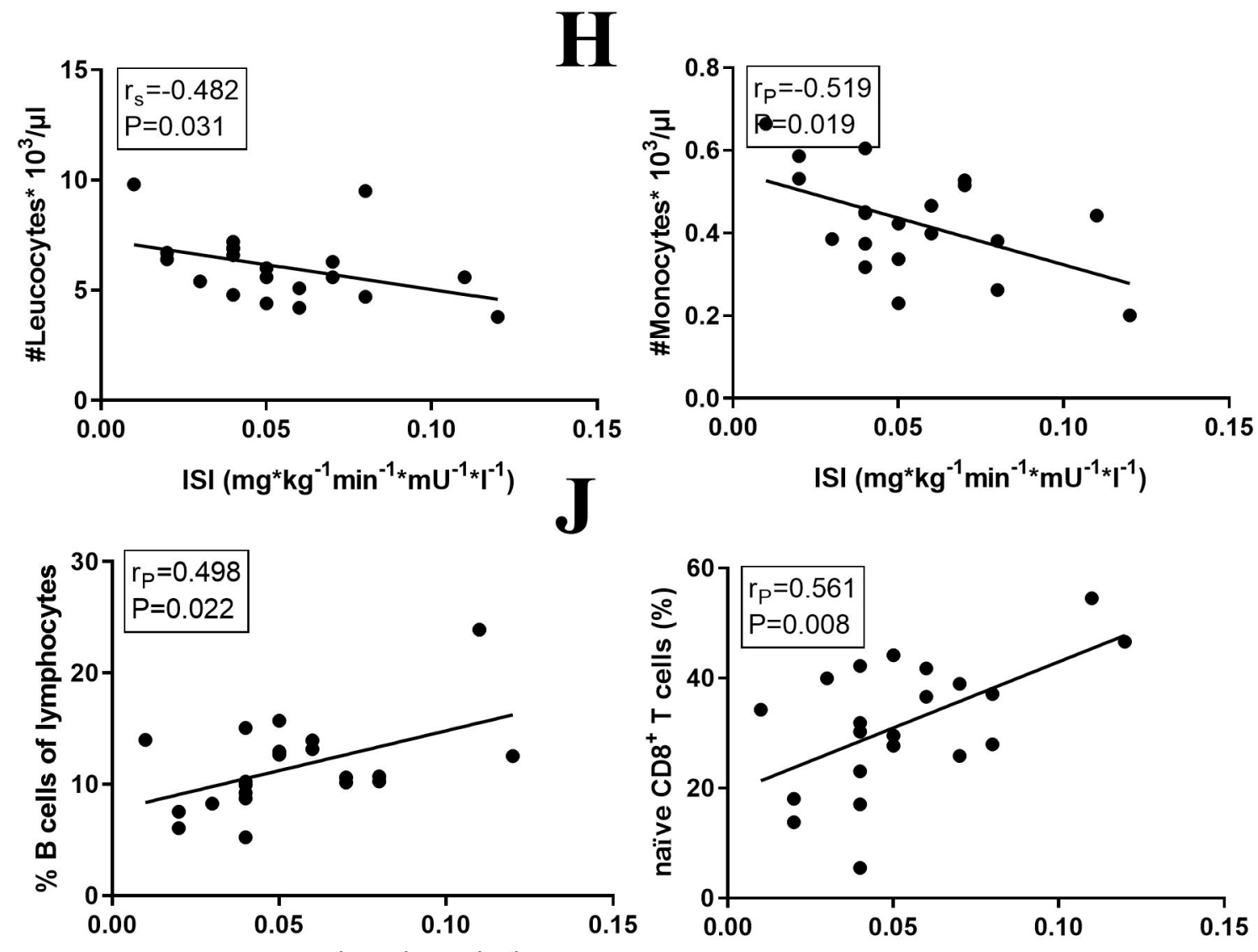

K

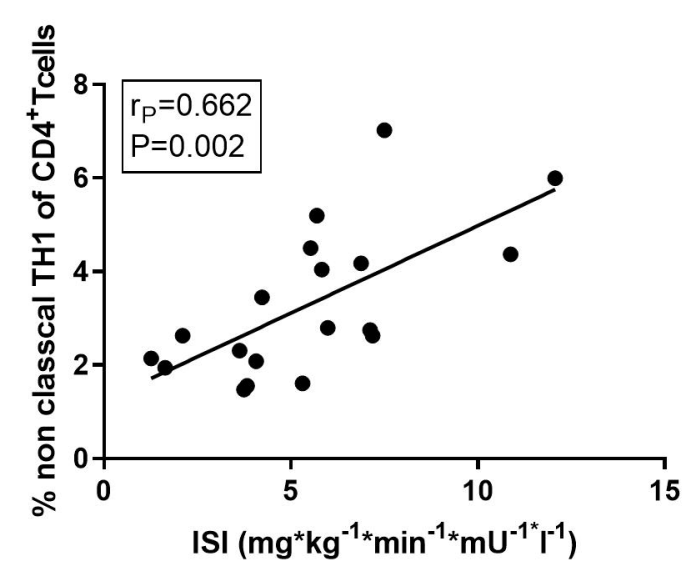

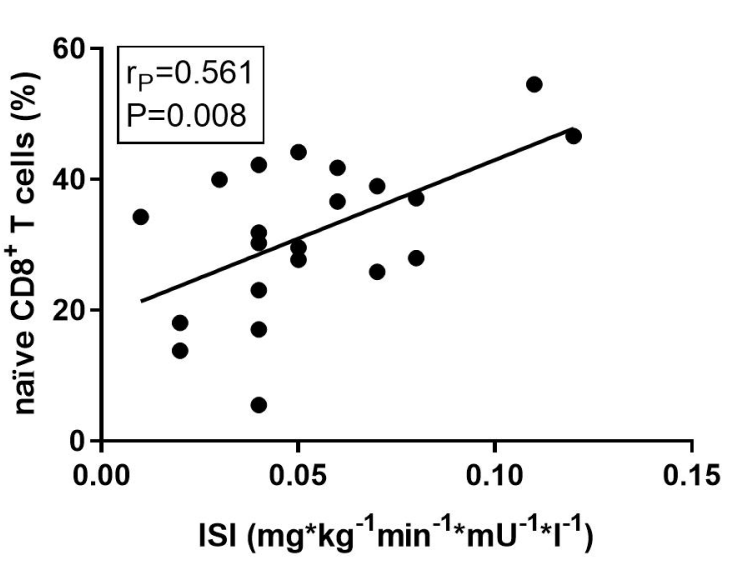

ISI $\left(\left.\mathrm{mg}^{\star} \mathrm{kg}^{-1} \mathrm{~min}^{-1 *} \mathrm{mU}^{-1 *}\right|^{-1}\right)$ 
A

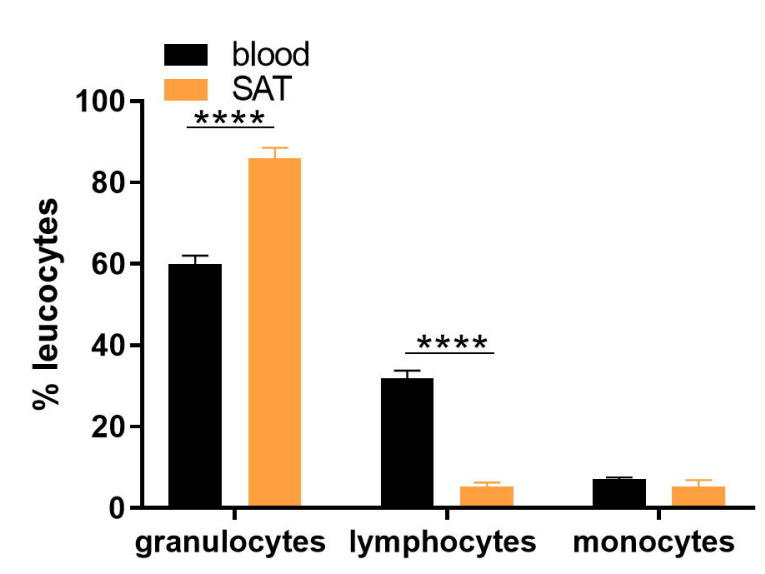

D
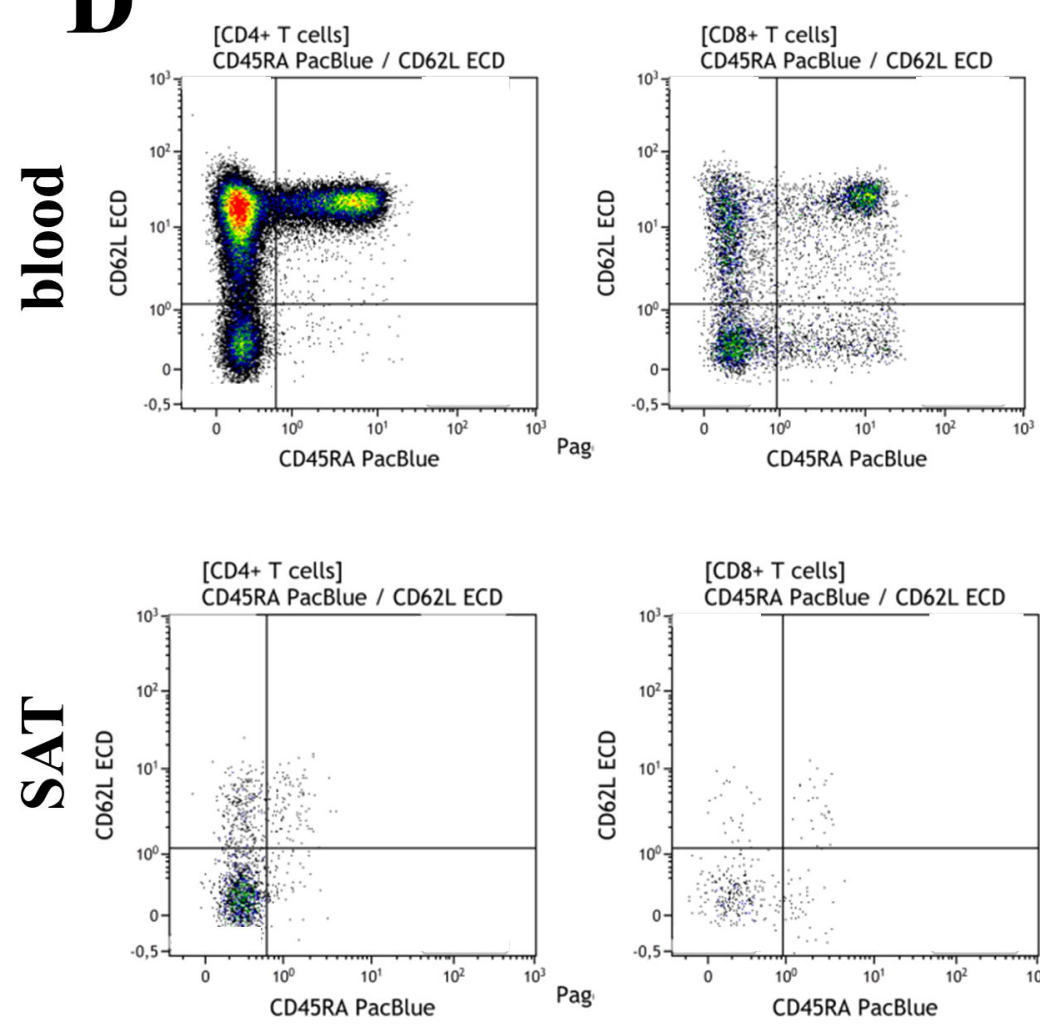

B

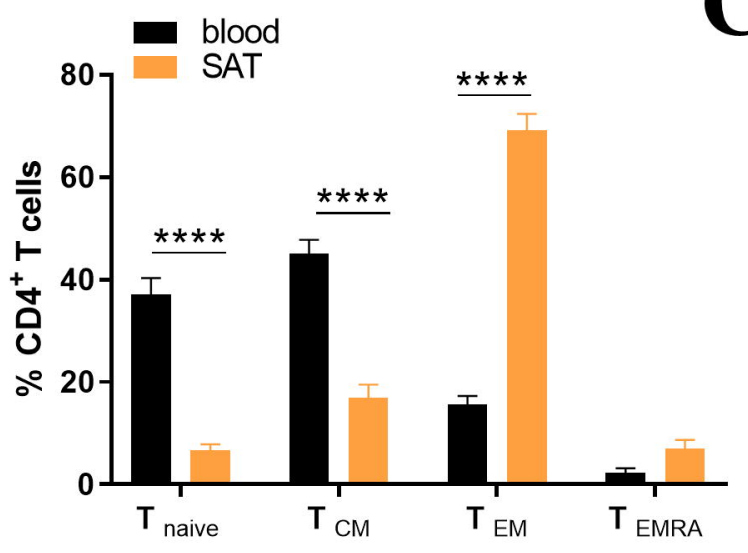

C

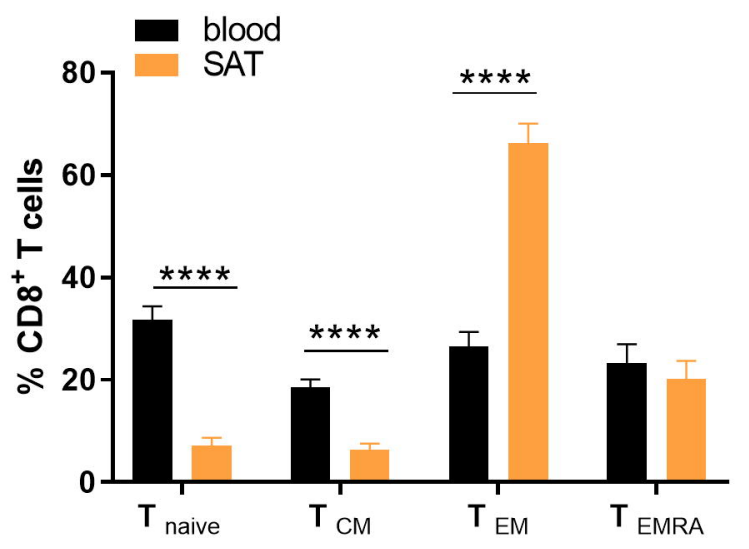

E

F
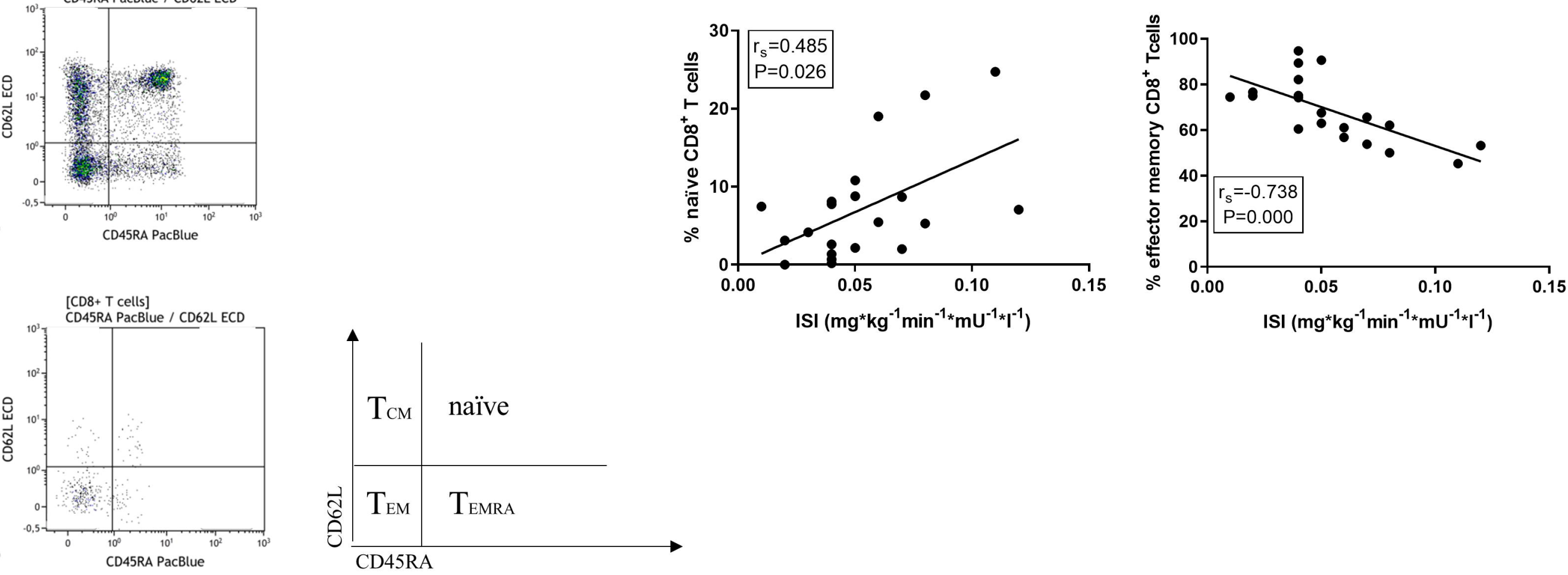
A

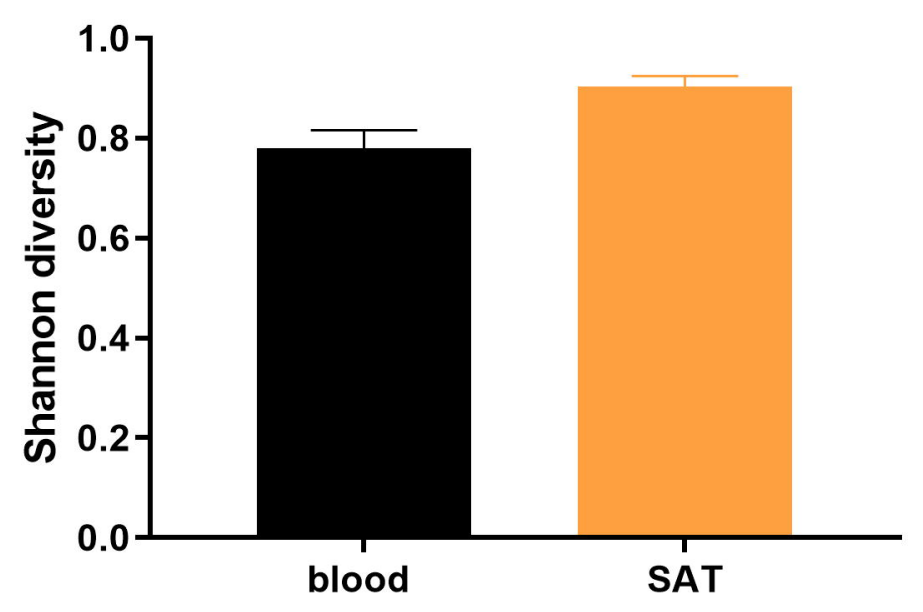

B
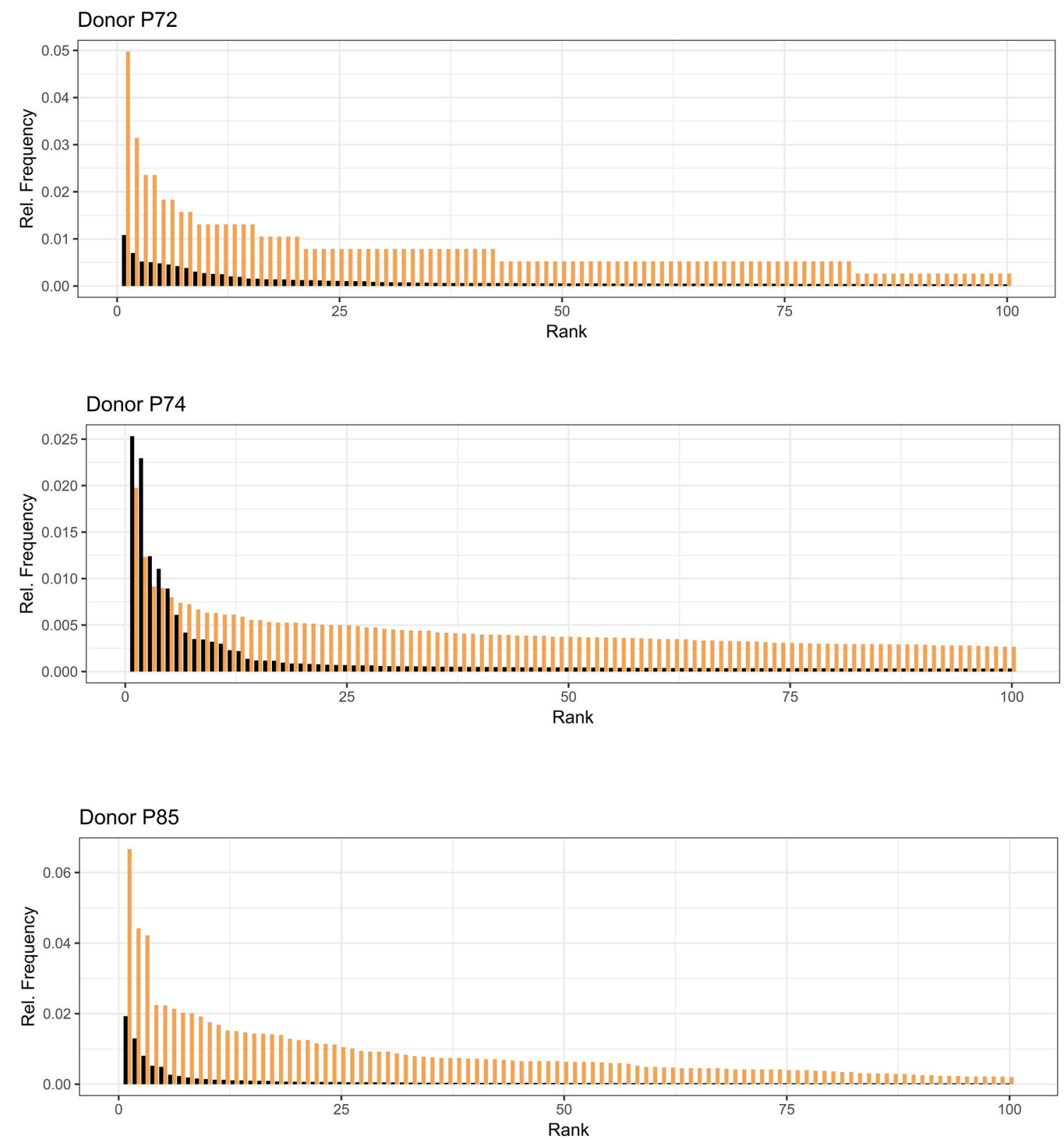
A

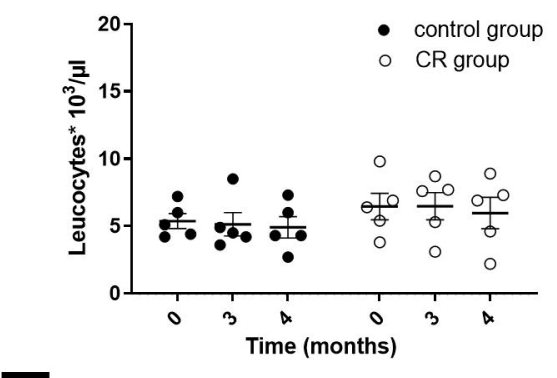

F

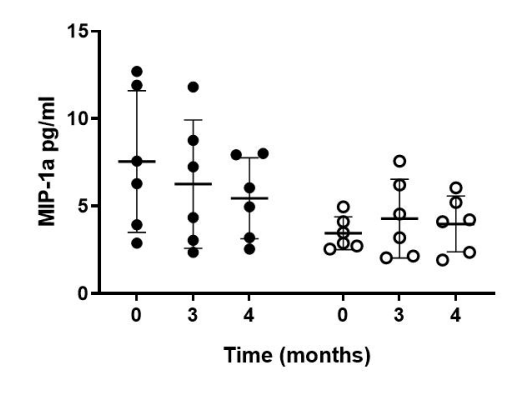

K
B

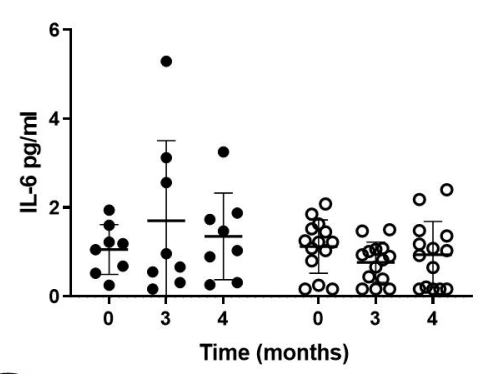

G

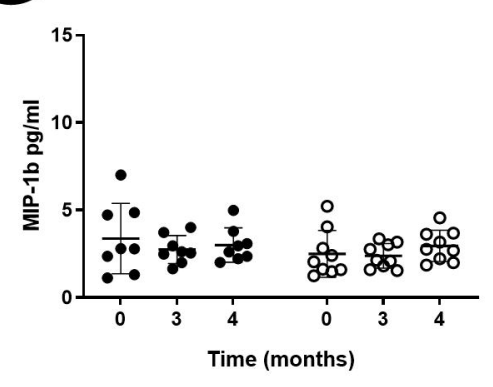

L
C
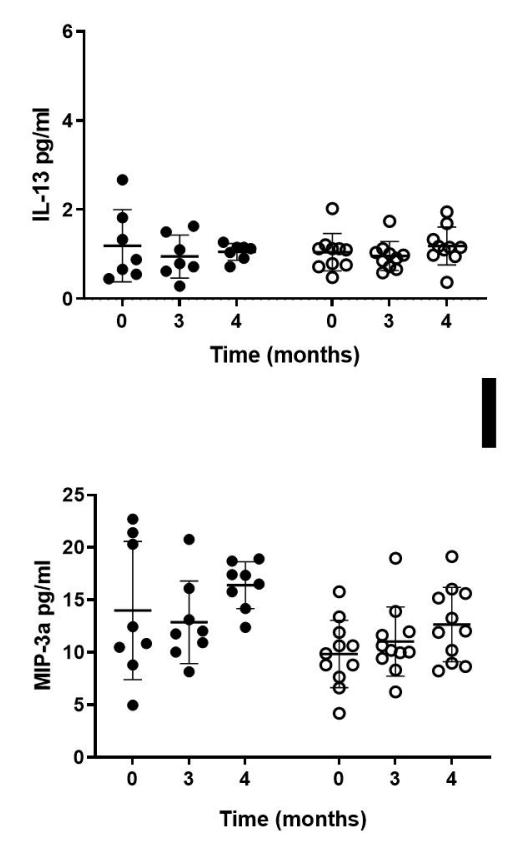

E
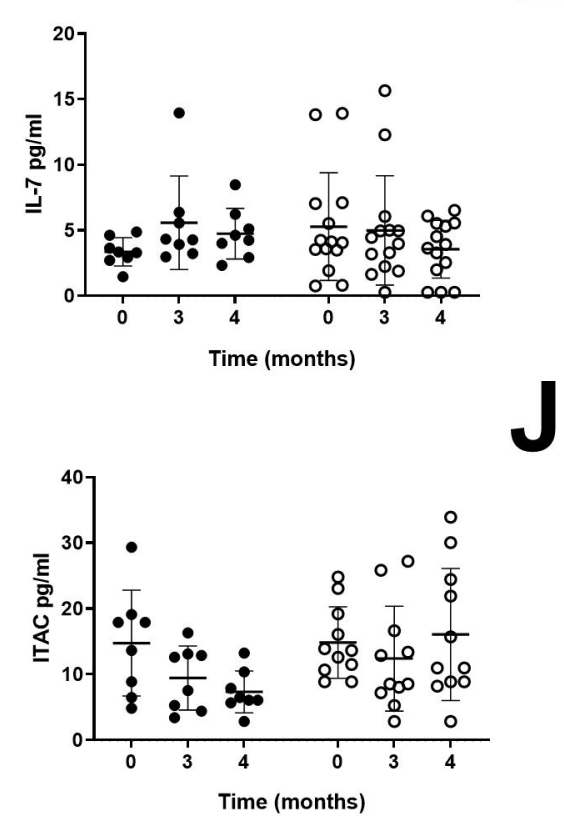

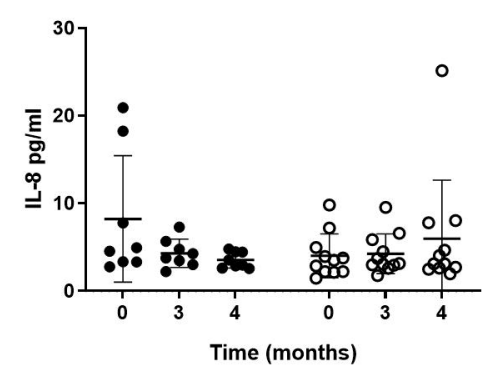

J

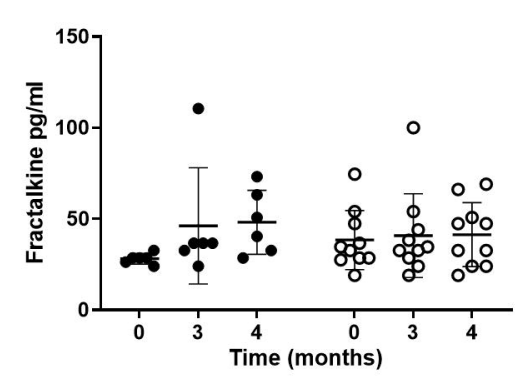

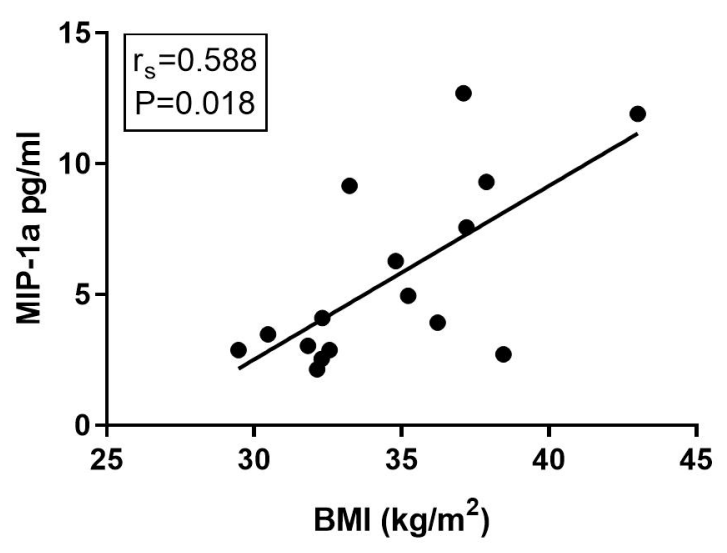

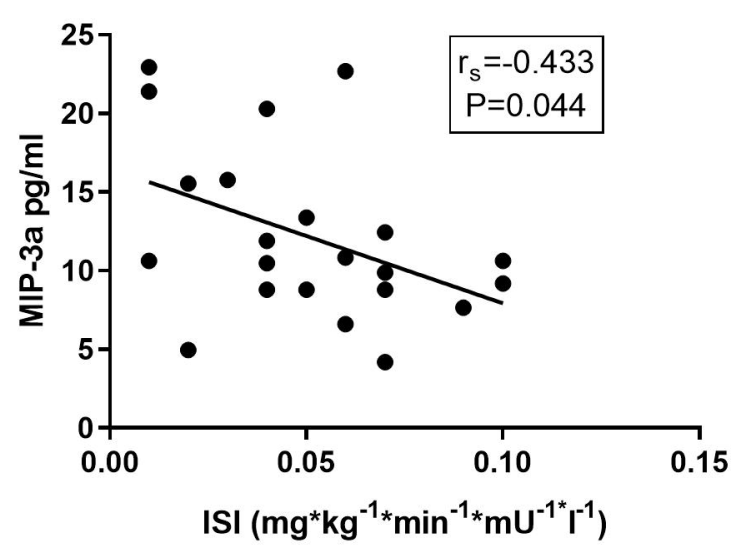

